\title{
Determining the sea-air flux of dimethylsulfide by eddy correlation using mass spectrometry
}

\author{
B. W. Blomquist ${ }^{1}$, B. J. Huebert ${ }^{1}$, C. W. Fairall ${ }^{2}$, and I. C. Faloona ${ }^{3}$ \\ ${ }^{1}$ University of Hawaii, Department of Oceanography, Honolulu, HI, USA \\ ${ }^{2}$ NOAA Earth System Research Laboratory, Physical Sciences Division, Boulder, CO, USA \\ ${ }^{3}$ Dept. of Land, Air and Water Resources, UC Davis, Davis, CA, USA
}

Received: 10 June 2009 - Published in Atmos. Meas. Tech. Discuss.: 24 August 2009

Revised: 9 December 2009 - Accepted: 14 December 2009 - Published: 8 January 2010

\begin{abstract}
Mass spectrometric measurement of DMS by atmospheric pressure ionization with an isotopically labeled standard (APIMS-ILS) is a sensitive method with sufficient bandpass for direct flux measurements by eddy correlation. Use of an isotopically labeled internal standard greatly reduces instrumental drift, improving accuracy and precision. APIMS-ILS has been used in several recent campaigns to study ocean-atmosphere gas transfer and the chemical budget of DMS in the marine boundary layer. This paper provides a comprehensive description of the method and errors associated with DMS flux measurement from ship platforms. The APIMS-ILS instrument used by most groups today has a sensitivity of 100-200 counts s ${ }^{-1} \mathrm{pptv}^{-1}$, which is shown to be more than sufficient for flux measurement by eddy covariance. Mass spectral backgrounds (blanks) are determined by stripping DMS from ambient air with gold. The instrument is found to exhibit some high frequency signal loss, with a half-power frequency of $\approx 1 \mathrm{~Hz}$, but a correction based on an empirically determined instrument response function is presented. Standard micrometeorological assumptions of steady state and horizontal uniformity are found to be appropriate for DMS flux measurement, but rapid changes in mean DMS mixing ratio may serve as a warning that measured flux does not represent the true surface flux. In addition, bias in surface flux estimates arising from the flux divergence is not generally significant in the surface layer, but under conditions of lowered inversion and high flux may become so. The effects of error in motion corrections and of vertical motion within the surface layer concentration gradient are discussed and the estimated maximum error from these effects is $\leq 18 \%$.
\end{abstract}

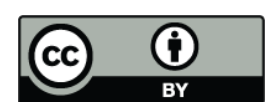

Correspondence to: B. Blomquist (blomquis@ hawaii.edu)

\section{Introduction and background}

The marine biogenic gas dimethylsulfide (DMS) is generally recognized as a major source of sulfate to the atmosphere, especially in the southern hemisphere where anthropogenic emissions are limited. Because of the role of sulfate aerosols in both direct and indirect climate forcing, the biogeochemical cycling of DMS has been studied extensively for several decades (e.g., Charlson et al., 1987; Fogelqvist, 1991; Falkowski et al., 1992; Bates et al., 1992; Andreae and Crutzen, 1997; Gabric et al., 2004). Gas transfer at the sea-air interface links the DMS biogeochemical cycle in the surface ocean to atmospheric aerosol production and cloud physics. Gas transfer mechanisms also play a central role in the carbon cycle through exchange of $\mathrm{CO}_{2}$, but adequate characterization of gas transfer has been an elusive goal.

The first analytical methods developed for DMS involved trapping the gas on adsorbents or with cryogens, followed by gas chromatography (GC) and sulfur-selective detection with a flame photometric detector (FPD) or sulfur chemiluminescent detector (SCD) (e.g., Barnard et al., 1982; Gregory et al., 1993; Ferek and Hegg, 1993; Bates et al., 2000). These methods are still widely used for studies of DMS and DMS-precursors in seawater (e.g., Kiene and Service, 1991; Kieber et al., 1996; Bates et al., 1994; Archer et al., 2002). A subsequent refinement of the GC method was the use of a mass spectrometer to discern between ambient DMS and an isotopically labeled internal standard, deuterated DMS, added continuously to the air sample (e.g., Bandy et al., 1993; Blomquist et al., 1993). All these methods, however, require sample integration times of minutes to tens of minutes for an acceptable detection limit at typical atmospheric concentrations.

Until recently, measurements of the DMS flux have been sparse and fraught with challenges. The most fundamental determination of atmospheric flux is obtained by eddy

Published by Copernicus Publications on behalf of the European Geosciences Union. 
correlation (EC), where the flux of a trace gas species is defined as the covariance of simultaneous measurements of vertical wind velocity and mixing ratio or concentration, $F=\overline{w^{\prime} c^{\prime}}$, where the prime denotes fluctuations from the mean and the overbar signifies a time average of sufficient length to capture turbulent frequencies contributing to the flux. In practice, the EC method requires rapid measurements (up to $20 \mathrm{~Hz}$ ) of both wind velocity and concentration, which is well beyond the capability of GC analysis.

There are other less direct approaches to flux measurement, such as gradient flux methods (GF) (Businger et al., 1971) and relaxed eddy accumulation (REA) (Businger and Oncley, 1990; Zemmelink et al., 2004a). While amenable to GC analysis, these methods are technically complex, requiring precisely controlled gas sampling systems. Putaud and Nguyen (1996) reported GF estimates of DMS flux from a ship, but interpretation of the derived transfer velocities was hindered by considerable variability in the results. Zemmelink et al. (2002) have studied the suitability of GF and REA for DMS flux measurements over the ocean in a nearshore environment and subsequently reported measurements obtained in the open sea during the FAIRS project on the spar platform R/P FLIP (Zemmelink et al., 2004b; Hintsa et al., 2004). While transfer velocity estimates from FAIRS were reasonable in comparison to commonly used gas transfer parameterizations, they report an unexplained bias between the two methods, with REA yielding fluxes up to 2 times higher than GF.

The recent development of a fast mass spectrometric method for DMS (Mitchell, 2001; Bandy et al., 2002) introduced the possibility of direct EC determinations of DMS flux. The first field deployments were aircraft-based studies of DMS in the marine boundary layer (Bandy et al., 2002). Ship-based studies are a logical application and considerable progress has been made in the correction of wind data for motion artifacts (Edson et al., 1998) such that EC is now frequently employed for $\mathrm{CO}_{2}$ flux measurements on ships (Fairall et al., 2000; McGillis et al., 2001, 2004; Miller et al., 2009; Taddei et al., 2009). Several studies of DMS sea-air exchange have been published to-date, yielding a huge increase in the catalog of DMS flux measurements and derived exchange velocities (Huebert et al., 2004; Blomquist et al., 2006; Marandino et al., 2007, 2008, 2009). Our group at University of Hawaii has thus far completed lengthy field programs in the equatorial Eastern Pacific, Sargasso Sea, Northeast Atlantic and Southern Ocean. Based on initial results, sea-air transfer of DMS shows less dependence on wind speed than predicted by power-law models derived from studies of more insoluble gases (e.g. $\mathrm{CO}_{2}, \mathrm{SF}_{6}, \mathrm{He}$ ) and this work holds considerable promise for diagnosing performance of more complex physics-based gas exchange models (Blomquist et al., 2006) and improving global flux estimates (Elliott, 2009).
Despite frequent use in field programs, a thorough description of the University of Hawaii APIMS method has yet to be published, especially with respect to the most recent developments. The motivation for this manuscript is to provide a comprehensive description of the fast DMS analytical method and its application to DMS flux measurement. While our emphasis is on ship-based measurements, the details of aircraft deployments are largely equivalent. For the interested reader, a more detailed description of the APIMS-ILS instrument is given in the Appendix.

\section{The APIMS-ILS method}

\subsection{Historical development}

Generating ions at atmospheric pressure is distinct from ionization at high vacuum. Charged particles from the primary ion source, usually a radioactive foil or high voltage corona discharge, first ionize the most abundant molecules (e.g. $\mathrm{N}_{2}$, $\mathrm{O}_{2}$ ). Subsequent molecular collisions and charge transfer rapidly lead to a state where only the most stable ions or ion clusters persist. The predominant ion species can often be controlled by introduction of specific compounds into the gas stream. Horning et al. (1973), for example, reported some of the first development work on atmospheric pressure mass spectrometric methods for drug and metabolite analysis, using benzene as the chemical ionization reagent species.

The energetics of the charge transfer reactions are usually insufficient to cause molecular dissociation. Dominant ions are typically parent molecular species or larger ion clusters (e.g. $\mathrm{C}_{6} \mathrm{H}_{6}^{+}$in the presence of benzene). In pure nitrogen or air, trace water vapor leads to the formation of water clusters, $\mathrm{H}^{+}\left(\mathrm{H}_{2} \mathrm{O}\right)_{n}$, as the dominant positive ion species (Good et al., 1970). Trace gas constituents with lower ionization potential or higher proton affinity than the dominant ions are ionized by charge or proton transfer.

Kelly and Kenny (1991) and Spicer et al. (1996) reported the first field measurements of DMS by atmospheric pressure chemical ionization (APCI) mass spectrometry. This instrument was an ambitious application of a triple quadrupole mass spectrometer and corona discharge ion source for aircraft-based atmospheric measurements (Spicer et al., 1994). Benzene was used as the chemical ionization reagent gas. Instrument response was sensitive to water vapor concentration and showed possible altitude dependence (pressure effects), but the data from the North Atlantic appear to be the first APCI mass spectrometric measurements of DMS from a field program. Note that with respect to nomenclature, we consider chemical ionization methods (APCI) to involve the deliberate introduction of a reagent gas (i.e. benzene in this example), while methods that do not are simply termed atmospheric pressure ionization mass spectrometry (APIMS). This is in general agreement with other published descriptions of these methods, but the distinction is not consistently maintained. 
Although operating at 1-2 Torr rather than atmospheric pressure, a proton transfer reaction mass spectrometer (PTRMS) (Lindinger et al., 1998) has also been used in aircraft studies. The PTR-MS ion source generates water clusters in a corona discharge. Dissociation of higher-order water clusters is assisted by gas expansion through an orifice from the corona source into a low pressure drift tube/reaction chamber where $\mathrm{H}_{3} \mathrm{O}^{+}$is the predominant ion. The comparatively low proton affinity of $\mathrm{H}_{3} \mathrm{O}^{+}$allows the PTR-MS to ionize a much broader range of organic species. Crutzen et al. (2000) and Williams et al. (2001) tentatively identified DMS in PTRMS mass scans over the rain forests in Surinam, but they rely on empirically determined rate constants rather than in-flight calibrations to estimate mixing ratios, and state the precision to be $\pm 30 \%$. Low source pressures yield lower sensitivity and thus far PTR-MS has not shown sufficient sensitivity for DMS flux measurements but Karl et al. (2009) suggest it may be possible for some organics.

Variable sensitivity is largely unavoidable in the atmospheric pressure source because charge transfer reactions are affected by changes in gas composition, pressure and temperature (Ketkar et al., 1991). Recognizing the value of an internal isotopic standard, which was shown to work well in GC-MS applications (Bandy et al., 1993), Bandy and colleagues subsequently developed an APIMS method with an isotopically labeled internal standard (APIMS-ILS) (Mitchell, 2001; Bandy et al., 2002). The labeled standard (d3-DMS), which is easily distinguished from the ambient molecular species by a mass spectrometer, provides a continuous measure of instrument sensitivity and constant correction for drift. Further, the constant, high concentration of labeled standard passivates adsorption sites in the inlet tubing, theoretically improving the transmission of the ambient DMS and the frequency response of the instrument. The high sensitivity and high data acquisition rate of the APIMS led to the first direct EC DMS flux measurements from aircraft (Bandy et al., 2002). On the subsequent DYCOMS-II field program, DMS flux measurements by APIMS-ILS were used to compute entrainment velocities at the cloud-top inversion of a stratocumulus-capped marine boundary layer (Stevens et al., 2003; Faloona et al., 2005).

\subsection{Ionization reactions}

Good et al. (1970) established the sequence and kinetics of ion formation in moist nitrogen at 4 Torr, leading from the initial ionized species, $\mathrm{N}_{2}^{+}$, to water clusters of the following form, where the distribution of clusters up to $\mathrm{H}^{+}\left(\mathrm{H}_{2} \mathrm{O}\right)_{n}$ depends on water vapor concentration, pressure and temperature.

$$
\begin{aligned}
& \mathrm{H}_{3} \mathrm{O}^{+}+\mathrm{H}_{2} \mathrm{O}+\mathrm{N}_{2} \rightleftharpoons \mathrm{H}^{+}\left(\mathrm{H}_{2} \mathrm{O}\right)_{2}+\mathrm{N}_{2} \\
& \mathrm{H}^{+}\left(\mathrm{H}_{2} \mathrm{O}\right)_{n-1}+\mathrm{H}_{2} \mathrm{O}+\mathrm{N}_{2} \rightleftharpoons \mathrm{H}^{+}\left(\mathrm{H}_{2} \mathrm{O}\right)_{n}+\mathrm{N}_{2}
\end{aligned}
$$

Proton affinity (or gas phase basicity) of the water clusters generally increases with size. Trace gas species, B, with higher proton affinity $\left(\geq 837 \mathrm{~kJ} \mathrm{~mol}^{-1}\right.$ or $200 \mathrm{kcal} \mathrm{mol}^{-1}$, such as nitrogen bases) are easily ionized by transfer of a proton or protonated water cluster.

$\mathrm{H}^{+}\left(\mathrm{H}_{2} \mathrm{O}\right)_{n}+\mathrm{B} \rightleftharpoons \mathrm{BH}^{+}\left(\mathrm{H}_{2} \mathrm{O}\right)_{m}+(n-m) \mathrm{H}_{2} \mathrm{O}, m=0 \quad$ to $n(\mathrm{R} 3)$

The proton affinity of DMS $\left(808 \mathrm{~kJ} \mathrm{~mol}^{-1}\right.$ or $193 \mathrm{kcal} \mathrm{mol}^{-1}$ ) is sufficiently low that it is not efficiently ionized when clusters larger than $\mathrm{H}^{+}\left(\mathrm{H}_{2} \mathrm{O}\right)_{3}$ predominate. Sunner et al. (1988a,b) discovered the sensitivity of many marginal compounds, including DMS, could be increased many orders of magnitude by heating the ionization source, thereby suppressing the formation of higher-order water clusters. In the case of DMS, the maximum increase in sensitivity was observed at a source temperature of $400^{\circ} \mathrm{C}$. In practice, maximum DMS sensitivity in the APIMS is achieved both by heating the source and by removing water vapor from the sample air with a Nafion membrane dryer (PermaPure PD-200T-24-MSS) (Bandy et al., 2002). Since DMS does not form hydrated ion clusters effectively (i.e. $m=0$ in R3), the product ion is simply $\mathrm{H}^{+} \mathrm{CH}_{3} \mathrm{SCH}_{3}$ (63 AMU). Figure 1 shows an APIMS mass spectrum of DMS in air.

\subsection{Backgrounds and detection limit}

The signal intensity at the mass of interest is a combination of desired signal (e.g. $\mathrm{H}^{+}$DMS ) and instrument background, often from unknown sources. Prior to computing a mixing ratio, the instrument backgrounds should be subtracted from the raw signals. When the APIMS-ILS method was first developed, background signals at masses 63 and 66 were measured in zero air, in the absence of either labeled or ambient DMS. This proved unsatisfactory because the introduction of dry zero air into the heated source alters the ionization equilibrium, such that backgrounds recorded in zero air are not necessarily equivalent to the ambient air background.

The ideal background measurement would be a DMS-free air sample, identical in all other respects to ambient air. The best approximation of this is achieved by stripping DMS from the sample air flow. Adsorption on gold has been used as a DMS sampling technique for many years (Barnard et al., 1982). Adapting this approach for blank measurements, we now use a $150 \mathrm{~cm}^{3}$ stainless steel cylinder (Swagelok 304L-HDF4-150) filled with gold-coated glass beads (3 mm Pyrex). The cylinder of gold-coated beads is valved into the sample flow under automated control of the data acquisition system for $3 \mathrm{~min}$ at the start of each hour. After two weeks of operation $(\approx 1000 \mathrm{~min}$. $)$ the trap is regenerated by heating to $300{ }^{\circ} \mathrm{C}$ under a flow of zero air for at least one hour. Break-through has not been observed, however, and longer operational periods may be feasible. 


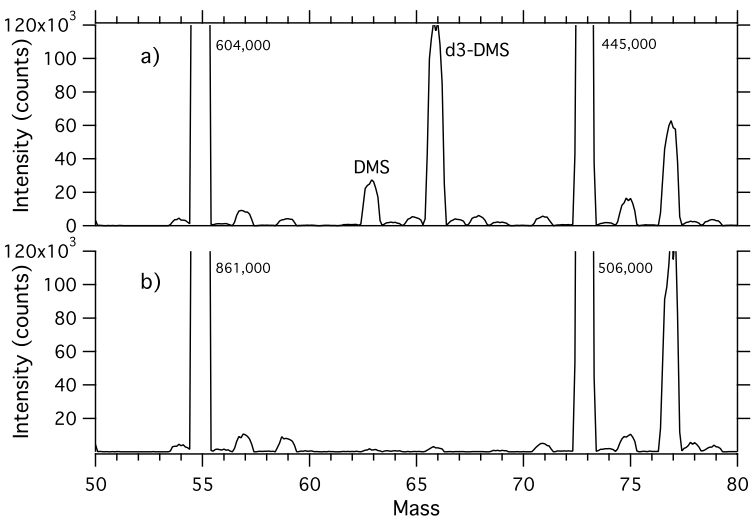

Fig. 1. Mass scans of ambient air with added d-3 DMS. Large water cluster peaks at masses 55 and 73 are the dominant ions. (a) Air sample. (b) Air sample through gold-bead blanking column, showing removal of DMS peaks at masses 63 and 66.

Figure 1 illustrates mass spectra for ambient air and goldbead background. Figure 2 presents raw count rate data for masses 63 and 66, illustrating the rapid decrease in signal when the gold-bead trap is activated. Backgrounds at mass 63 measured with this system in a recent field program were $\approx 1 \%$ of raw signal levels. The mass spectra in Fig. 1 show an increase in background signal at other masses in the absence of DMS, however, reflecting a shift in the ionization equilibrium when DMS is not actively competing for protons. This effect is smaller than would be the case if zero air were employed for blank measurement, but it does suggest backgrounds measured with the gold bead trap may be slightly overestimated. As long as background levels remain low, this should not be a significant source of error.

Pulse counting is used for detection because the signal level is usually too low for efficient analog detection. In this mode, sensitivity is defined as counts s${ }^{-1} \mathrm{pptv}^{-1}$. Typical sensitivities are 100-200 counts $\mathrm{s}^{-1} \mathrm{pptv}^{-1}$ yielding a count rate of about $80000-160000$ counts s $^{-1}$ for an internal standard mixing ratio of 800 pptv and $8000-16000$ counts s $^{-1}$ for a typical ambient mixing ratio of $80 \mathrm{pptv}$. Theoretical noise levels from counting statistics for the ambient signal at $1 \mathrm{~Hz}$ bandpass would be $\sigma=\sqrt{8000}$ or $\approx 1 \%$ of the mean signal level. Actual noise levels are somewhat larger (see Sect. 4.1).

In principle, for an analytical signal with a significant degree of white noise, the detection limit may be decreased by averaging over successively longer integration times. Continuous improvement in the detection limit will be realized until instrumental drift becomes a larger contributor to signal variance than noise, at which point further averaging will not improve the detection limit and it may even worsen. Werle et al. (1993) describe a method for determining the optimal averaging time for analytical systems subject to both noise and drift. For APIMS-ILS, the continuous internal standard provides rigorous correction of most sources of instrumental

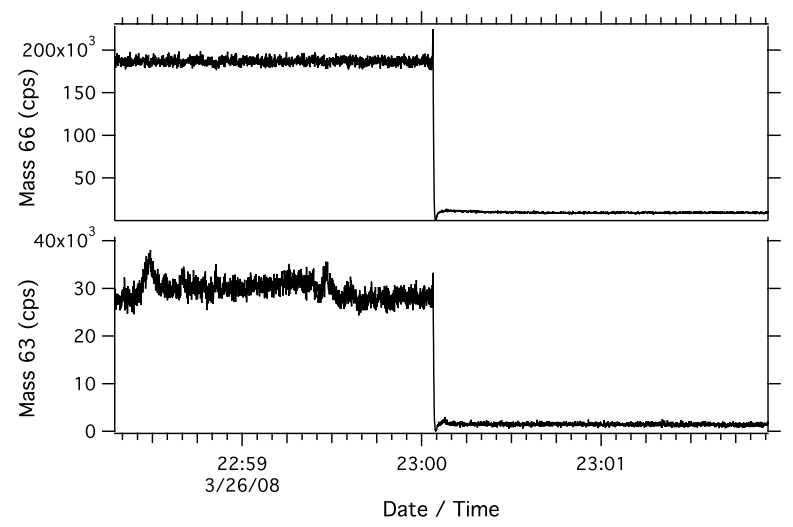

Fig. 2. Raw signals (counts $s^{-1}$ ) for ambient DMS and internal standard (masses 63 and 66, respectively). The gold bead DMS trap was activated shortly after $2300 \mathrm{~h}$, illustrating the response time and background signal levels.

drift, but variance in mass spectral backgrounds and calibration drift in gas flow rate meters will contribute to measurement drift. Flow meter drift is quite small over the time scales under consideration here $(\approx 1 \mathrm{~h})$ as is the spectral background drift. In theory, therefore, very low sub-pptv DMS detection limits are achievable through signal averaging. More pertinent to the subject of this paper, however, is the effect of random noise on the flux error, which has been investigated by Lenschow and Kristensen (1985) and will be addressed in Sect. 6.

\subsection{Isotopomer distributions}

Material used for the labeled standard is not $100 \%$ d-3 DMS. Other isotopomers arising from ${ }^{34} \mathrm{~S},{ }^{13} \mathrm{C}$ and variable deuterium substitution are also present. Natural DMS exists as a number of isotopomers for the same reasons. In principle, if the isotopomeric distributions of both standard and ambient samples are precisely known, the ambient mixing ratio can be calculated exactly from the observed 63/66 signal ratio and standard mixing ratio, as shown in the following section.

Isotopomeric abundances for the standard are obtained from mass scans of d-3 DMS in zero air over the mass range 63 to $68 \mathrm{AMU}$, corresponding to DMS isotopomers from 62 to $67 \mathrm{AMU}$. Abundances for natural DMS isotopomers may be obtained from mass scans of reagent-grade DMS in zero air or, alternatively, calculated from natural elemental abundances. We have not noticed a significant difference in measured and theoretical abundances for natural DMS.

Raw mass scan peak intensities are first corrected by subtraction of a zero-air-only background. The abundance of each isotopomer $\left(\mathrm{A}_{n}\right)$ is then computed from the corrected mass intensities (1), where $\mathrm{I}_{n}$ is the background-corrected 
signal intensity of each of the $n$ isotopomers. Abundances determined during a recent field project are shown in Table 1.

$\mathrm{A}_{n}=\frac{\mathrm{I}_{n}}{\sum_{i=63}^{68} \mathrm{I}_{i}}, n=63 \rightarrow 68$

\subsection{Computing mixing ratio}

The background-corrected signal intensity at mass $n$ may be expressed as the sum of contributions from ambient and labeled standard isotopomers, where $C$ is mixing ratio and $\varepsilon$ is the absolute efficiency of the mass spectrometer.

$\mathrm{I}_{n}=\varepsilon\left(\mathrm{A}_{n, \mathrm{amb}} C_{\mathrm{amb}}+\mathrm{A}_{n, \mathrm{std}} C_{\mathrm{std}}\right)$

Assuming analytical efficiency is equivalent for both species, taking the ratio $(R)$ of intensities at masses 63 and 66 eliminates $\varepsilon$, which is unknown, and this is the principal advantage of using an isotopic internal standard.

$R=\frac{\mathrm{I}_{63}}{\mathrm{I}_{66}}=\frac{\mathrm{A}_{63, \mathrm{amb}} C_{\mathrm{amb}}+\mathrm{A}_{63, \mathrm{std}} C_{\mathrm{std}}}{\mathrm{A}_{66, \mathrm{amb}} C_{\mathrm{amb}}+\mathrm{A}_{66, \mathrm{std}} C_{\mathrm{std}}}$

Solving for $C_{\mathrm{amb}}$ and inserting the measured abundance constants (Table 1) yields a relationship for ambient mixing ratio in terms of the corrected signal intensity ratio and internal standard mixing ratio. From Table 1 we note $A_{66, a m b}$ is not significant and may be ignored.

$$
\begin{aligned}
C_{\mathrm{DMS}, \mathrm{amb}} & =C_{\mathrm{DMS}, \mathrm{std}}\left(\frac{R \mathrm{~A}_{66, \mathrm{std}}-\mathrm{A}_{63, \mathrm{std}}}{\mathrm{A}_{63, \mathrm{amb}}-R \mathrm{~A}_{66, \mathrm{amb}}}\right) \\
& =C_{\mathrm{DMS}, \mathrm{std}}\left(\frac{0.8742 R-0.0110}{0.9298}\right)
\end{aligned}
$$

\subsection{Primary calibration and internal standard}

Cylinders of labeled d-3 DMS are prepared commercially (Scott-Marrin, Inc.). The primary calibration reference is a DMS permeation device (VICI Metronics) maintained in the lab at constant temperature $\left(50^{\circ} \mathrm{C}\right)$ and verified by gravimetric data. The gas flow control system (Sect. A3) incorporates a permeation tube oven, allowing field calibrations of the d3 DMS compressed gas standard. Ship-board calibrations serve as a secondary check on the cylinder concentration.

Calibration runs are typically done in clean dry air from a zero air generator (Matheson Chrysalis II), bypassing the Nafion air dryer. Residual moisture in zero air is usually sufficient to produce a strong DMS signal, but additional moisture may be added if necessary. The standard concentration is calculated from the known mixing ratio of unlabeled DMS emitted by the permeation tube using the relationship given above (4).
Table 1. Isotopomeric abundances for the labeled standard and ambient DMS. Indicated masses are protonated DMS (molecular weight +1 ). Precision is estimated to be \pm 0.0010 .

\begin{tabular}{lllllll}
\hline & $\mathrm{A}_{63}$ & $\mathrm{~A}_{64}$ & $\mathrm{~A}_{65}$ & $\mathrm{~A}_{66}$ & $\mathrm{~A}_{67}$ & $\mathrm{~A}_{68}$ \\
\hline d-3 DMS Std & 0.0110 & 0.0059 & 0.0411 & 0.8742 & 0.0281 & 0.0397 \\
Ambient DMS & 0.9298 & 0.0293 & 0.0403 & 0.0004 & 0.0001 & 0.0000 \\
\hline
\end{tabular}

\section{Raw data corrections}

\subsection{Motion correction}

Corrections to wind data for platform motion are required on both ships and aircraft. Motion corrections for shipbased EC flux systems have been described by Edson et al. (1998). Lenschow and Spyers-Duran (1987) describe correction methods for aircraft data. Only a qualitative overview of the ship correction algorithm will be presented here.

On a ship, wind and motion sensors are subjected to both linear displacements and angular rotations on all 3 axes. Pitch, roll and vertical motion are usually large, while yaw is less significant. In the first step of the motion correction algorithm, angular corrections are applied to bring both wind and acceleration measurements into a fixed frame of reference with respect to the earth's surface. As described by Edson et al. (1998), a gravity vector derived from low-pass filtered 3-axis accelerometer response is used as the reference for deriving slow roll and pitch angles. Slow rotation about the vertical axis (yaw) is derived from low-pass filtered gyro compass or GPS heading data. Final pitch, roll and yaw angles are the sum of the slow angle component and high-pass filtered signals from 3-axis angular rate sensors. The complete angular correction is then applied to the raw acceleration and wind data, and the gravity component is removed from accelerometer data.

Linear platform velocities are finally obtained by integration of the angle-corrected linear acceleration data, using high-pass filtering to remove integration drift. Subtracting the derived platform velocities from the angle-corrected wind data yields motion-corrected winds $(u, v$ and $w)$ in ship coordinates. At this point, bringing the mean relative wind into the streamline can be accomplished by rotating wind coordinates to achieve zero mean vertical wind velocity $(\bar{w})$ and crosswind component $(\bar{v})$. The corrected vertical wind velocity is now suitable for flux computations.

\subsection{Phase correction}

An additional adjustment is necessary to synchronize the measurements. A time lag between the in-situ wind measurement and DMS response exists due to the length of the APIMS inlet line $(25 \mathrm{~m})$. At typical flow rates of 100 
$120 \mathrm{Std} \mathrm{L} \mathrm{min}{ }^{-1}$ the lag is $\approx 1-1.5 \mathrm{~s}$. However, when wind and DMS concentration signals are logged by separate data systems, poor synchronization and clock drift can add an additional time shift between the two data series. A phase correction is therefore necessary and two approaches may be used to determine the lag time.

A direct approach involves the introduction of a spike or other signal perturbation at the inlet (e.g., Bariteau et al., 2009), yielding a direct measure the response lag. This method is somewhat complicated, usually requiring additional hardware and plumbing at the mast-mounted inlet. If response lag is variable the procedure must be repeated on a regular basis and it does not account for clock synchronization problems. When the flux signal is weak, however, this approach may be the most reliable measure of inlet lag time.

The flux signal for DMS is usually strong, so a lag correlation computed for DMS mixing ratio and vertical wind (Fig. 3) provides a better measure of phase shift in that it accounts for all sources of time lag and is computed independently for each data segment.

\section{Spectral characteristics and frequency response}

\subsection{Signal variance}

As described in Sect. 2.3, the APIMS signal is obtained by counting pulses from an ion multiplier, and the ambient DMS concentration is proportional to the number of counts recorded in a finite time interval: typically 25 milliseconds at $20 \mathrm{~Hz}$ bandpass when both ambient and standard signals are determined sequentially. The number of counts is usually small during this interval and random counting error is thus the major source of signal variance. Counting error variance manifests as a nearly-white noise spectrum with a slope of +1 on a plot of $\log f S_{x x}(f)$ vs. $\log f$. Figure 4 presents a comparison of the variance spectra for DMS and $w$, illustrating the spectral effect of random uncorrelated noise in the computed DMS mixing ratio.

Atmospheric variance in the DMS signal may be estimated by extrapolating the exponential decay in autocovariance back to zero time lag $(\zeta=0)$ (or, more conveniently and almost as accurate, as just the magnitude of the second point in the autocovariance series). Uncorrelated, random noise contributes only to the first point in the autocovariance plot, so the difference between this point and extrapolated atmospheric variance at $\zeta=0$ is an estimate of the white noise variance. Figure 5 illustrates this analysis for an hourly segment of $20 \mathrm{~Hz}$ DMS. In this case, atmospheric variance (and possibly other sources of non-white noise variance) is $29 \mathrm{pptv}^{2}$. White noise variance is approximately $57 \mathrm{pptv}^{2}$ $\left(\sigma_{\mathrm{dms} \text {,noise }}=7.6 \mathrm{pptv}\right)$ and constitutes about two-thirds of the observed signal variance.

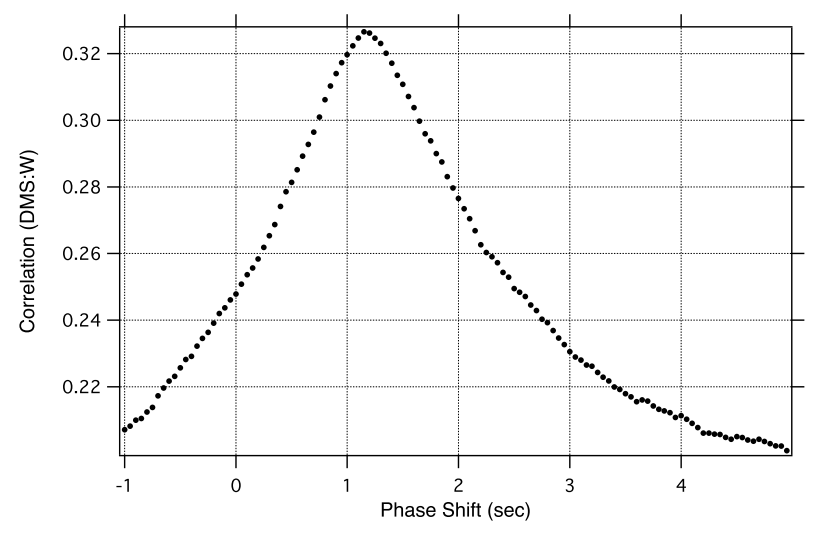

Fig. 3. Lag correlation between DMS and $w$. The peak in correlation shows the DMS signal is lagged by $1.15 \mathrm{~s}$ with respect to vertical wind velocity.

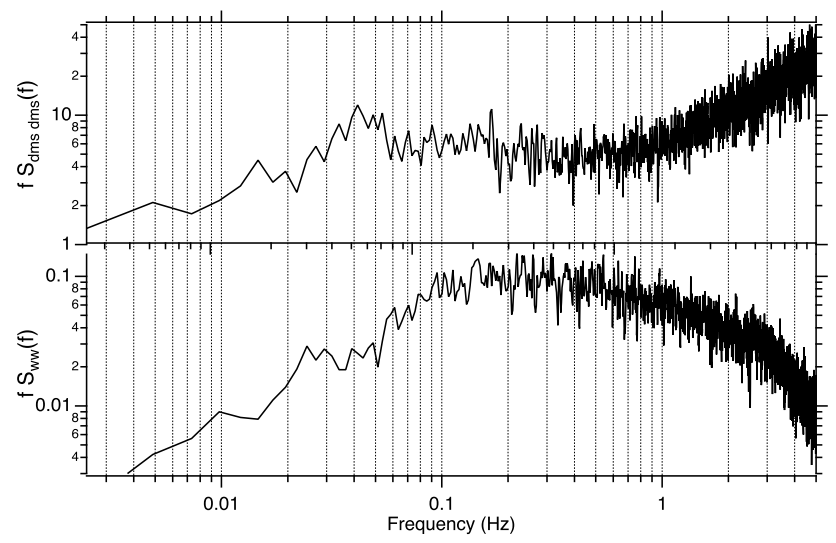

Fig. 4. Variance spectra for DMS (top) and vertical wind velocity ( $w$, bottom) plotted in $\log f S_{x x}(f)$ vs. $\log f$ format. The negative slope of the inertial subrange apparent in the $w$ spectrum is not a feature of the DMS spectrum due to the white noise contribution. Spectra are $1 \mathrm{~h}$ averages. $\overline{u_{r}} \approx 14 \mathrm{~ms}^{-1} . \quad F_{\mathrm{dms}}$ $\approx 4.4 \mu$ moles $\mathrm{m}^{-2} \mathrm{~d}^{-1}$.

The mass 66 signal is typically filtered, therefore counting statistics for the mass 63 signal are the principle source of white noise in the final measurement. The expected $\sigma_{\mathrm{dms}}$,noise can be computed assuming $\sigma_{\text {cnts }_{63}}=\sqrt{\text { cnts }_{63}}$, where $\overline{\text { cnts }_{63}}$ is the mean number of counts at mass 63 over $25 \mathrm{msec}$ intervals. Over a $24 \mathrm{~h}$ period of hourly flux measurements on the Souther Ocean GASEX program, we compute the mean $\sigma_{\mathrm{dms}, \text { noise }}=8.4 \mathrm{pptv}$ from autocovariance and $6.8 \mathrm{pptv}$ from mass 63 counting statistics. A slightly higher result from autocovariance likely reflects a small amount of additional white noise variance from other sources. 


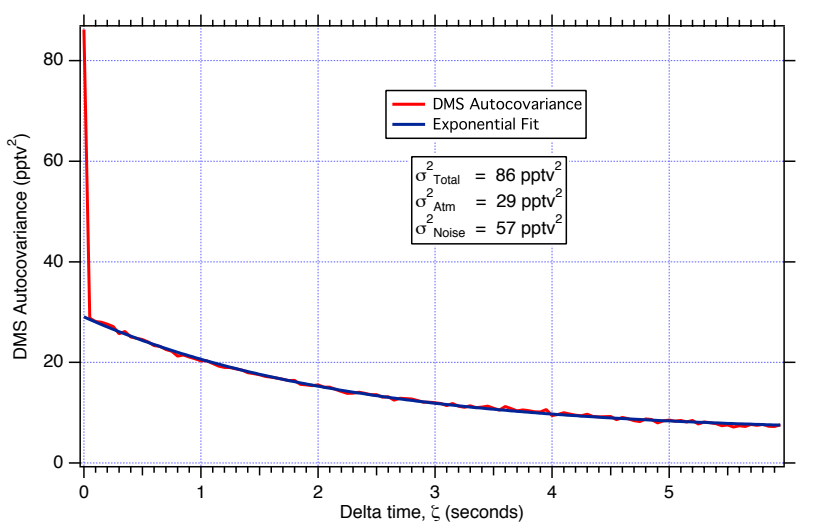

Fig. 5. Autocovariance plot for a DMS signal. Exponential extrapolation to $\zeta=0$ yields an estimate for atmospheric variance, $\sigma_{\mathrm{atm}}^{2} \approx 29 \mathrm{pptv}^{2}$. An white noise contribution of $\sigma_{\text {noise }}^{2} \approx 57 \mathrm{pptv}^{2}$ represents the major fraction of observed signal variance (see Sect. 4.1).

\subsection{Cospectra}

Computation of the covariance in DMS and $\mathrm{W}$ is the final step in measuring the sea-air flux. Cospectra in the atmospheric surface layer exhibit a distinctive form under neutral or stable conditions which is a function of wind speed, measurement height and atmospheric stability (Kaimal et al. , 1972). The theoretical shape for the cospectrum is not well defined at low frequencies for unstable conditions, however, and this region is further affected by random noise over short averaging periods. The integrated area (covariance) is the flux, the magnitude of which has a direct dependence on the sea water DMS concentration.

Averaging cospectra over long time intervals is facilitated by normalizing to sea water DMS concentration and constant Schmidt number. Figure 6 shows normalized cospectra, binaveraged by wind speed, for the Southern Ocean GASEX program. A gradual progression in the spectral maximum with wind speed is evident, as is the apparent loss of a small amount of flux signal at the highest frequencies. The causes for signal attenuation are investigated in the next section and corrections are discussed in Sect. 6.4.

\subsection{Inlet attenuation}

Attenuation of mixing ratio fluctuations by inlet tubing has been studied by Lenschow and Raupach (1991). With respect to the requirements of EC flux measurements, they conclude attenuation caused by moderate lengths of inlet tubing does not significantly limit flux measurements when inlet flow is maintained in a fully turbulent state $(\operatorname{Re}>2300)$. The use of an air dryer in the APIMS sample stream creates a more complex inlet, however, so an empirical determination of instrument response is desirable.
Lenschow and Raupach (1991) studied the effects of inlet length on humidity fluctuations using dual sensors, measuring variability in water vapor concentration near the entrance and exit of several inlet configurations. Lacking dual sensors, our investigation compares APIMS instrument response for two inlet systems in separate trials: (1) A full $25 \mathrm{~m}$ teflon inlet manifold ( 0.375 in. ID) with subsample flow through the Nafion dryer (PermaPure PD-200T-24-SS) and a short tube $(0.3 \mathrm{~m} \cdot 0.17$ inch ID teflon) into the APIMS source. (The dryer consists of a parallel bundle of 200 Nafion tubes, each 0.042 inch ID.24 in long, in a stainless steel shell.) And (2), a short (1 m) inlet manifold with the same subsample tubing connecting directly to the APIMS source, omitting the Nafion dryer. In both cases the main manifold flow was maintained at $100-120 \mathrm{std} \mathrm{L} \mathrm{min}^{-1}$ and subsample flow through the dryer and APIMS source was $4 \mathrm{std} \mathrm{L} \mathrm{min}^{-1}$.

Room air was sampled with the long inlet. Because of the need to exclude water vapor in the absence of a dryer, dry nitrogen was sampled by the short inlet system. A constant flow of labeled standard was added at the front of the inlets. A 3-way fast-switching solenoid valve, driven by a clock pulse from the data acquisition system, introduced a pulsed flow at the front of each inlet from a permeation tube of unlabeled DMS. Permeation gas flow was maintained at a constant rate and switched between the inlet and a dump line at frequencies up to $3 \mathrm{~Hz}$. DMS concentrations were calculated as described above. In all trials, the APIMS data acquisition rate was $20 \mathrm{~Hz}$.

A series of runs at switching frequencies from 0.1 to $3 \mathrm{~Hz}$ was obtained for each inlet. Signal response for the short inlet yielded a somewhat rounded square wave with a small amount of amplitude attenuation at the highest frequency, possibly due to response characteristics of the switching valve. Overall, instrument response with the short inlet system was very fast and for our purposes represents an unattenuated signal. In contrast, observations with the long inlet and dryer show noticeable signal attenuation as the frequency is increased.

The DMS variance spectra show distinct peaks at the run frequencies. A response ratio (5) was computed for each frequency using the integrated area of the spectral peaks, and the results are plotted in Fig. 7.

$\Phi^{2}\left(f_{n}\right)=\frac{\int_{f_{n}-\delta}^{f_{n}+\delta} S_{x x, \text { long }}(f) d f}{\int_{f_{n}-\delta}^{f_{n}+\delta} S_{x x, \text { short }}(f) d f}$

The observed half-power frequency from Fig. 7 is $\approx 1 \mathrm{~Hz}$. Response roll-off is more gradual and begins at a lower frequency than the Lenschow and Raupach (1991) result for a simple straight tube inlet. Theoretical attenuation curves for straight sections of tubing, equivalent in length to the actual inlet manifold and subsample tubing, are shown in Fig. 7 and predict considerably less attenuation than the observed response curve for the inlet system including the dryer. 

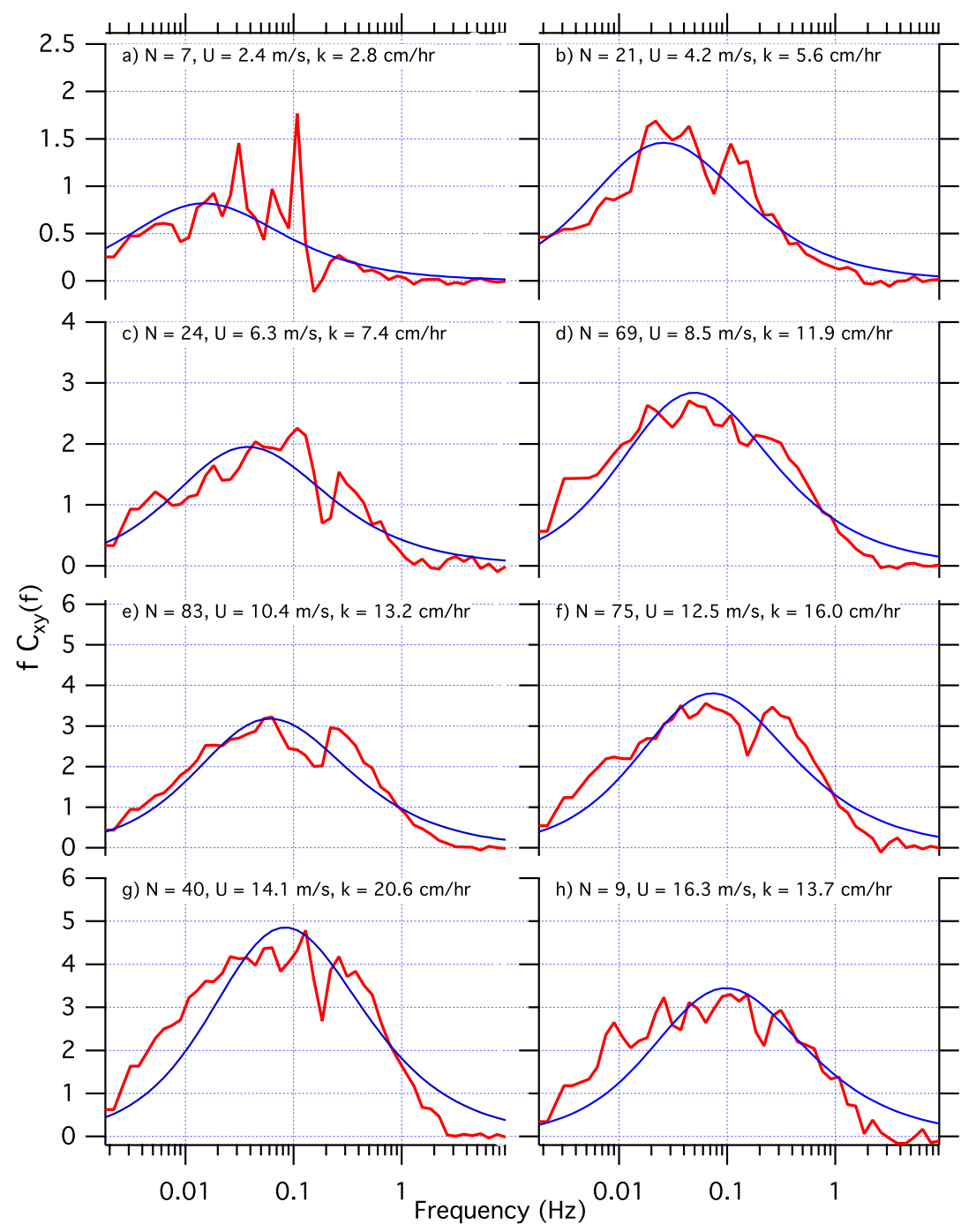

Fig. 6. Mean normalized cospectra, computed from hourly $w$ :dms cospectra normalized to sea water DMS concentration, adjusted to $S c=660$ and binned by mean $10 \mathrm{~m}$ wind speed. For comparison, the blue trace shows the expected theoretical cospectral shape for neutral conditions at the bin-centroid wind speed and $z=18 \mathrm{~m}$, scaled to the area of the observed spectrum.

Subsequent tests of the long inlet without the dryer show a frequency response similar to the short inlet, confirming the expectation that the tubing alone does not attenuate response significantly at high flow rates. The empirical response function in Fig. 7 can be used to correct for high frequency losses, as discussed in Sect. 6.4. The input function for this test is an approximate square wave, however, which may roll off at a slightly higher frequency than the response for a true sinusoidal input, and additional corrections discussed in Sect. 6.4 may be desirable.

\section{Micrometeorological issues affecting flux accuracy}

DMS has a sole source in the surface layer of the ocean, is generally well-mixed in the marine boundary layer, and under most conditions has near-zero concentration in the overlying free troposphere. For studies of air-sea gas exchange, the desired quantity is the flux of DMS at the ocean surface, which is always positive (i.e. out of the ocean). Measurements in the surface micro-layer are not practical, however, so flux is determined at some distance, $z$, above the surface, typically $15-20 \mathrm{~m}$ on a bow jackstaff or sampling tower. We anticipate flux at this height will not be significantly different from the true surface flux, but several assumptions are necessary for this to be true. 


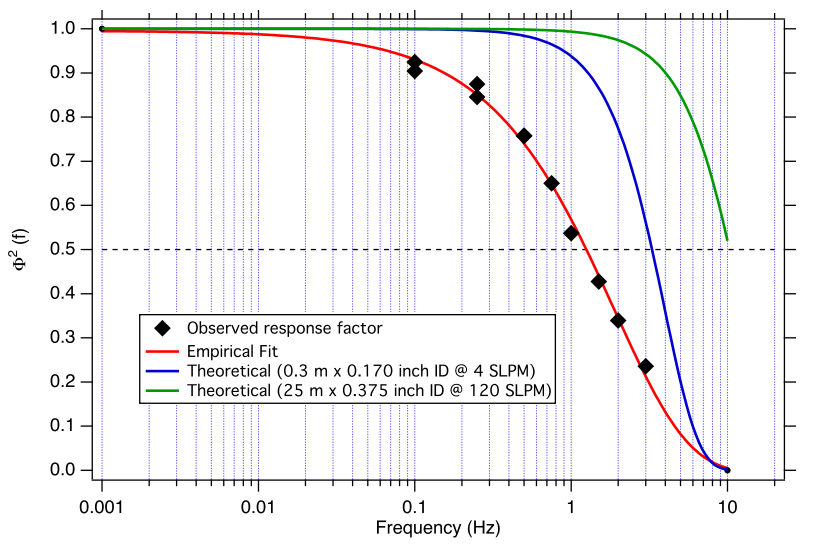

Fig. 7. Response ratio $\Phi^{2}(f)$ for the APIMS inlet and Nafion dryer as a function of frequency. The red curve represents a least-squares fit to a two-parameter empirical function of the form $\Phi^{2}(f)=\exp \left(-a f^{b}\right)$, where $a=0.557$ and $b=0.917$. Instrument response at $0.001 \mathrm{~Hz}$ and $10 \mathrm{~Hz}$ is assumed to be 1 and 0 , respectively. The intersection of the horizontal line with the curve shows a half-power frequency of $\approx 1 \mathrm{~Hz}$. Also shown are theoretical attenuation for a $0.3 \mathrm{~m}$ straight section of 0.17 inch ID tubing @ $4 \mathrm{Std} \mathrm{L} \mathrm{min}^{-1}$ and a $25 \mathrm{~m}$ straight section of 0.375 inch ID tubing @ $120 \mathrm{Std} \mathrm{L} \mathrm{min}^{-1}$ (Lenschow and Raupach, 1991).

The conservation equation for DMS in the marine boundary layer can be written as in (6), where the term $\frac{\partial}{\partial x_{i}} u_{i}$ represents the full turbulent wind field $(u, v$, and $w), D$ is the molecular diffusion coefficient for DMS in air and $L$ is the photochemical destruction rate (here we assume $L=0$ at night).

$\frac{\partial c}{\partial t}+\frac{\partial}{\partial x_{i}} u_{i} c=D \frac{\partial^{2} c}{\partial x_{i}^{2}}-L$

Separating $c$ and $u_{i}$ into mean and fluctuating components $\left(c=\bar{c}+c^{\prime}\right.$, etc.) and averaging over time (assuming ergodicity) yields (7).

$\frac{\partial \bar{c}}{\partial t}=-\frac{\partial}{\partial x_{i}} \overline{u_{i}} \bar{c}-\frac{\partial}{\partial x_{i}} \overline{u_{i}^{\prime} c^{\prime}}+D \frac{\partial^{2}}{\partial x_{i}^{2}} \bar{c}-\bar{L}$

This reduces to (8) assuming horizontal gradients in DMS are negligible and $\bar{w}=0$.

$\frac{\partial \bar{c}}{\partial t}=-\frac{\partial}{\partial z} \overline{w^{\prime} c^{\prime}}+D \frac{\partial^{2}}{\partial z^{2}} \bar{c}-\bar{L}$

Under conditions of steady state $\left(\frac{\partial c}{\partial t}=0\right)$ and neglecting the loss term, $L,(8)$ reduces to (9).

$\frac{\partial}{\partial z}\left(\overline{w^{\prime} c^{\prime}}\right)=D \frac{\partial^{2}}{\partial z^{2}} \bar{c}$

Turbulent flux vanishes at the surface and diffusive flux is negligible compared to turbulent flux above the surface microlayer, so integration of (9) from the surface to $z$ leads to
(10), which equates the desired quantity, surface flux, which is impossible to measure directly, to the turbulent flux at $z$, which is measurable.

$\left(\overline{w^{\prime} c^{\prime}}\right)_{z}=-D\left(\frac{\partial \bar{c}}{\partial z}\right)_{0}$

Businger (1986) has discussed the assumptions leading to (10) with respect to dry deposition particle flux and we will now examine them for the specific case of DMS.

\subsection{Entrainment and the flux gradient}

The concentration of DMS in the free troposphere is near zero, which leads to a significant entrainment flux at the marine boundary layer inversion height, $z_{i}$. The magnitude of the resulting flux gradient will depend on the relative magnitudes of the surface and entrainment fluxes, $F_{0}$ and $F_{i}$, respectively. In most cases, $F_{0}>F_{i}$, leading to an increasing concentration of DMS within the boundary layer in the absence of chemical loss, typically observed at night. Assuming negligible advection, constant $L$ with height, and a well mixed boundary layer, $\left(\overline{w^{\prime} c^{\prime}}\right)_{z}$ can be expressed as a linear function of $F_{0}$ and $F_{i}(11)$, which can be rearranged to yield the fractional error in assuming $\left(\overline{w^{\prime} c^{\prime}}\right)_{z} \equiv F_{0}(12)$.

$\left(\overline{w^{\prime} c^{\prime}}\right)_{z}=F_{0}\left(1-\frac{z}{z_{i}}\right)+F_{i} \frac{z}{z_{i}}$

$\frac{\Delta_{F_{0}, \text { est }}}{F_{0}} \equiv\left(\frac{\left(\overline{w^{\prime} c^{\prime}}\right)_{z}}{F_{0}}-1\right)=\frac{z}{z_{i}}\left(\frac{F_{i}}{F_{0}}-1\right)$

As an estimate of the flux error we assume the following typical conditions:

(1) $z_{i}=800 \mathrm{~m}$ and $z=18 \mathrm{~m}$

(2) Transfer velocity, $k_{\mathrm{dms}}=15 \mathrm{~cm} \mathrm{hr}^{-1}=4.17 \times 10^{-5} \mathrm{~ms}^{-1}$ and the sea-air concentration difference, $\Delta[\mathrm{DMS}] \approx[\mathrm{DMS}]_{\mathrm{sw}}=1 \mu$ mole $\mathrm{m}^{-3}, \quad$ therefore $F_{0, \mathrm{DMS}}=\mathrm{k}_{\mathrm{dms}}[\mathrm{DMS}]_{\mathrm{sw}}=3.6 \mu$ moles $\mathrm{m}^{-2} \mathrm{~d}^{-1}=1 \mathrm{pptv} \mathrm{m} \mathrm{s}^{-1}$

(3) $[\mathrm{DMS}]_{\mathrm{mbl}}=80$ pptv, entrainment velocity, $w_{e}=-0.005 \mathrm{~m} \mathrm{~s}^{-1}$ and $F_{i, \mathrm{DMS}}=w_{e} \Delta C$.

The concentration jump, $\Delta C$, is defined as the difference in DMS concentration across the inversion, $[\mathrm{DMS}]_{f t}-[\mathrm{DMS}]_{\mathrm{mbl}}$, or in this case $\Delta C=-80 \mathrm{pptv}$ and thus $F_{i, \mathrm{DMS}}=0.4 \mathrm{pptv} \mathrm{ms}^{-1}$. Under these conditions the estimated fractional error from (12) is only $-1.4 \%$. However, as $z_{i}$ decreases to $200 \mathrm{~m}$ the error increases to $\approx-5.4 \%$. In situations where $z_{i}$ is reduced and $F_{0} \gg F_{i}$, the error could exceed $-10 \%$. 


\subsection{Steady state and horizontal uniformity}

To examine further issues related to assumptions dealing with steady state, advection, and chemical loss we integrate all terms in (7) from the surface to measurement height, $z$. To simplify the result, we take the $x$ to be along the mean wind $(\bar{v}=0)$ and define the column mean values for variables such that $1 / z \int_{0}^{z}(\bar{c}) d z \equiv \hat{\bar{c}}$, etc.

$\left(\overline{w^{\prime} c^{\prime}}\right)_{z}=-\frac{\partial \hat{\bar{c}}}{\partial t} z-\frac{\partial}{\partial x} \widehat{\bar{u} \bar{c}} z-\frac{\partial}{\partial x} \widehat{\bar{u}^{\prime} c^{\prime}} z+D\left(\frac{\partial \bar{c}}{\partial z}\right)_{0}-\widehat{L} z$

The first term on the right hand side is the rate of change in the column concentration. The second term is advective flux from a horizontal gradient in DMS concentration and the third, horizontal turbulent flux, is typically small relative to the second and may be ignored. Inspection of (13) reveals that in the limit $z \rightarrow 0$, the extra terms vanish. But, as Businger (1986) points out, it is not possible to measure $\left(\overline{w^{\prime} c^{\prime}}\right) z$ under this condition, and if even if we could, the result would not be representative of a significant area of sea surface.

Alternately, if the following measurement conditions are met, we see the additional terms in (13) become negligibly small.

$\frac{\partial \hat{\bar{c}}}{\partial t}, \frac{\partial \widehat{\bar{u}}}{\partial x}, \widehat{L} \ll \frac{F_{0}}{z}$

Evaluating the right side of inequality (14) using the measurement conditions of Sect. 5.1 yields $\left(F_{0} / z\right)=200 \mathrm{pptv} \mathrm{hr}^{-1}$. From a practical standpoint, only $\partial \hat{\bar{c}} / \partial t$ in (14) is easily measured and is typically much less than $200 \mathrm{pptvhr}^{-1}$, as is the expected daytime photochemical loss rate $\left(\widehat{L} \approx 5-6 \mathrm{pptv} \mathrm{hr}^{-1}\right)$. Thus, assumptions in the derivation of (10) seem largely justified. Furthermore, $\partial \hat{\bar{c}} / \partial t \approx F_{0} / z$ does not necessarily indicate $\left(\overline{w^{\prime} c^{\prime}}\right)_{z}$ differs significantly from the surface flux, as other terms in (13) may have opposite signs and could largely cancel. But, as Businger (1986) concludes, criteria such as (14) are useful for quality control. Rapid changes in mean concentration in space and time should be viewed as a warning flag indicating the measured flux may differ significantly from the true surface flux.

\subsection{Residence time}

Another useful criterion discussed by Businger (1986), and related to the suitability of the steady state assumption, is residence time, which in practice should be much greater than the flux measurement time. Neglecting advection, the residence time for a scalar such as DMS can be written as the ratio of the column concentration to the rate of change in column concentration due to flux divergence and chemical loss (15). Evaluating this for the typical measurement conditions given earlier yields $t_{\mathrm{dms}} \approx 24 \mathrm{~h}$, which is much longer than the hourly averaging time used in this work and supports the assumption of steady state.

$t_{c}=\frac{-\hat{\bar{c}} z_{i}}{\frac{\partial \hat{\bar{c}}}{\partial t} z_{i}}=\frac{-\hat{\bar{c}} z_{i}}{F_{0}-F_{i}-\widehat{L} z_{i}}$

\section{Uncertainty, flux corrections and quality control}

Uncertainty in the determination of transfer velocity $\left(k_{\mathrm{dms}}\right)$ includes error from several sources, both random and systematic, in the measurements of covariance flux and sea water DMS concentration. Error in the estimate of water-side DMS concentration is often difficult to assess because the measurement is usually made at some depth, and concentration gradients near the surface are not easily sampled. Nevertheless, error in the flux measurement is often the largest contributor to the overall uncertainty in $k_{\mathrm{dms}}$. In this section we examine some of the factors influencing flux error, describe corrections where necessary and possible, and discuss quality control criteria for filtering bad values.

\subsection{Flux error}

The uncertainty in covariance of vertical velocity, $w$, and some scalar, $c$, may be expressed as

$\Delta F_{c}=\frac{a \sigma_{w} \sigma_{c}}{\sqrt{T / \min \left(\tau_{w}, \tau_{c}\right)}}$

where $\sigma$ is the standard deviation, $\tau$ is the integral (decorrelation) time scale, $T$ the sample integration time, and $a$ is a constant variously reported as 1 or 2 (e.g., Fairall et al., 2000; Lenschow and Kristensen, 1985). The constant $a$ in this form reflects the uncertain nature of the relationship arising from approximations to the form of the autocorrelation functions and the interactions of the two variables. Because there are two variables here, there are two time scales. The appropriate time scale is generally taken to be the shorter of the two (generally $\tau_{w}$ ) or as the square root of the product of the two, $\tau_{w c}$.

We assume the wind speed measurement is relatively noise-free, but the scalar measurement is often subject to multiple sources of variance. Assuming the sources of variance are independent, we may expand (16) to the following form.

$$
\Delta F_{c}=\frac{a \sigma_{w} \sigma_{c_{a}}}{\sqrt{T / \tau_{w c_{a}}}}\left[1+\frac{\sigma_{c_{n}}^{2} \tau_{c_{n}}}{\sigma_{c_{a}}^{2} \tau_{w c_{a}}}\right]^{1 / 2}
$$

Here we consider two sources of variance in $c$, atmospheric turbulence $\left(c_{a}\right)$ and white noise $\left(c_{n}\right)$. We have normalized by the first process and allow a different time scale and variance for each process. 
There are various approaches for determining the integral time scales, $\tau_{x}$, defined as the integral of the autocorrelation function of $x(18)$, where $R_{x}(\zeta)=\overline{[x(t)-\bar{x}][x(t+\zeta)-\bar{x}]}$ is the autocovariance of $x$ as a function of time shift, $\zeta$.

$\tau_{x}(\zeta) \equiv \frac{1}{\sigma_{x}^{2}} \int_{0}^{\infty} R_{x}(\zeta) d \zeta$

In the surface layer, $\tau_{w}$ is often approximated as in (19) where $z$ is the observation height and $\overline{u_{r}}$ the relative wind speed.

$\tau_{w}=b z / \overline{u_{r}}$

The coefficient $b$ is fairly uncertain, but is a function of $(z / L)$; on the order of 10 in unstable conditions and 3 in near-neutral conditions. The integral time scale may also be estimated from the peak frequency $\left(f_{\max }\right)$ in the $w$ variance spectrum or, alternatively, the $w c$ cospectrum.

$\tau_{x}=1 / 2 \pi f_{\max }$

We can also compute the integral time scale for the case of band-limited white noise arising from electronic noise or Poisson counting statistics $\left(\tau_{c_{n}}\right)$. Band-limited white noise is characterized by a constant variance-spectral value, $\phi_{c_{n}}$, from $f=0$ to a maximum frequency, $f_{x}$.

$\phi_{c_{n}}(f)=\phi_{c_{n}}, f<f_{x}$

$\phi_{c_{n}}(f)=0, \quad f>f_{x}$

We may compute the autocorrelation function of the noise (Fourier transform of the spectrum) and integrate to get $\tau_{c_{n}}$, as in (18). However, in this case it is simpler to use the relationship between the integral time scale and the value of the variance spectrum at $f=0$.

$\sigma_{c_{n}}^{2} \tau_{c_{n}}=\frac{\phi_{c_{n}}(0)}{4}=\frac{\phi_{c_{n}}}{4}$

Substitution of (22) into (17) yields the following expression for the absolute error of the covariance.

$\Delta F_{c}=\frac{a \sigma_{w} \sigma_{c_{a}}}{\sqrt{T / \tau_{w c_{a}}}}\left[1+\frac{\phi_{c_{n}}}{4 \sigma_{c_{a}}^{2} \tau_{w c_{a}}}\right]^{1 / 2}$

Some parameters in (23) are stability dependent. MoninObhukov similarity scaling may be used to show the stability dependence of variances through the following relationships, where $L$ is the Obukhov length in meters and $u_{*}$ is the friction velocity. In addition, following (19), an empirical relationship may be used to describe the stability dependence of $\tau_{w c_{a}}$, where $b$ is now a constant. $\sigma_{w}=1.25 u_{*} f_{w}(z / L)$

$\sigma_{c_{a}}=\frac{\overline{w^{\prime} c^{\prime}}}{u_{*}} 3.0 f_{c}(z / L)$

$\tau_{w c_{a}}=b \frac{z}{\overline{u_{r}}} f_{\tau}(z / L)$

The functions $f_{w}$ and $f_{c}$ are similarity relationships describing $z / L$ dependence.

$f_{w}(z / L)=(1+3|z / L|)^{1 / 3}, \quad z / L<0$

$f_{w}(z / L)=1+0.2 z / L, \quad z / L>0$

$f_{c}(z / L)=(1+20|z / L|)^{-1 / 3}, \quad z / L<0$

$f_{c}(z / L)=1+1.0(z / L)^{1 / 2}, \quad z / L>0$

One coauthor (Fairall) has studied the stability dependence of $\tau_{w c}$ using flux observations made from R/P Flip during the SCOPE field program, in an Eastern Pacific stratocumulus regime. Estimates of $\tau_{w c}$ were obtained from $f_{\max }$ of cospectra $\left(f C_{w c}(f)\right)$ and from individual variance spectra (where $f_{\max }=\sqrt{f_{\max , c} f_{\max , w}}$ ). A fit to these data yields a value of $b=2.8$ in (24c) and the following empirical relationship for $f_{\tau}(z / L)$.

$f_{\tau}(z / L)=\left[\min (5, \max (0.5,(1+0.6 z / L))]^{-1}\right.$

Equations (24a)-(27) allow an estimate of $\Delta F_{c}$ from (23) in terms of $u_{*}, \mathrm{~L}, \phi_{c_{n}}$ and $\overline{u_{r}}$. Figure 8 shows the stability dependence of (23) for typical conditions: $z=18 \mathrm{~m}, \overline{u_{r}}=8 \mathrm{~m} \mathrm{~s}^{-1}$, $u_{*}=0.28 \mathrm{~m} \mathrm{~s}^{-1}, F_{0}=1$ pptv $\mathrm{m} \mathrm{s}^{-1}\left(3.6 \mu\right.$ moles $\left.\mathrm{m}^{-2} \mathrm{~d}^{-1}\right)$, and $\phi_{c_{n}}=4 \mathrm{pptv}^{2} \mathrm{~Hz}^{-1}$. In general, uncertainty is much larger under stable atmospheric conditions $(z / L>0)$ and for this example the contribution from white noise is seen to be less than $10 \%$ of the total error.

For DMS, several parameters in (23) are conveniently estimated directly from the measurements. The turbulent variance in DMS, $\sigma_{c_{a}}$, may be estimated as the square root of the second point in DMS autocovariance, as illustrated in Fig. 5, and $\sigma_{w}$ is computed directly from motion corrected wind data. $\phi_{c_{n}}$ in (23) may be estimated as the mean of the DMS variance spectrum from 5 to $10 \mathrm{~Hz}$, where white noise from counting statistics predominates. For the APIMS, $\phi_{c_{n}}$ 
is typically in the range of $1-7 \mathrm{pptv}^{2} \mathrm{~Hz}^{-1}$. Accurate determination of $\tau_{w c}$ over hourly timescales is subject to considerable uncertainty, however, and we therefore use the empirical relationships in (24c) and (27).

Figure 9 shows a comparison between computed error from (23) and the observed scatter in the observations $(n=329)$ during the Southern Ocean GASEX project. Results are binned versus $10-\mathrm{m}$ neutral wind speed $\left(U_{10 \mathrm{~N}}\right)$. Obukhov length $(L)$ and $U_{10 \mathrm{~N}}$ are obtained from standard output of the NOAA COARE bulk flux model (Fairall et al., 1996, 2003). To compensate for environmental sources of variance in the observations, we have normalized the observed flux and computed flux error to sea water DMS concentration, and further restrict observations to a narrow sea surface temperature range which includes the bulk of the Southern Ocean measurements $\left(\mathrm{SST}=4-7^{\circ} \mathrm{C}\right.$ ). Because the observations were largely Lagrangian, following a patch of tracer in the ocean surface layer, environmental variability was minimized. Computed errors were squared before bin averaging. The square root of the bin average computed error variance was further normalized to yield relative error. As a measure of the scatter in the direct observations, we present both the relative standard deviation ( $\mathrm{RSD}=\sigma / \mu$ ) and relative halfwidth of the distribution (one-half the difference between the 15 th and 85th percentiles divided by the mean) for each wind speed bin. Figure 9 therefore presents the computed relative error and observed RSD or distribution half-width in DMS transfer velocity over a limited temperature range, binned by wind speed. We find the computed error is in general agreement with or slightly less than the observed scatter in the observations when the constant $a=2$ in Eq. (23). To the extent the RSD of the observations includes variance not explicitly considered in the error computation, we might expect the computed error to be slightly less than the observed scatter.

\subsection{Density-related flux corrections}

Webb et al. (1980) discuss density related effects of water vapor and temperature fluctuations on in-situ flux measurements. Due to the effects of latent and sensible heat flux, $\bar{w}$ is not precisely zero, so we cannot ignore the mean component of flux: $\bar{w} \bar{c}$. In general, this error is not serious for scalar species like DMS with a short atmospheric lifetime, where the magnitude of the flux signal, $c^{\prime}$, is a significant fraction of $\bar{c}$. For example, $\bar{w}$ can be on the order of $10^{-4} \mathrm{~ms}^{-1}$ and under these conditions the error in DMS flux would be $\approx(100 \mathrm{pptv})\left(10^{-4} \mathrm{~ms}^{-1}\right)=10^{-2} \mathrm{pptv} \mathrm{m} \mathrm{s}^{-1}$, representing a $1 \%$ error on a typical flux of 1 pptv m s $\mathrm{m}^{-1}$. This is in contrast to long-lived species such as $\mathrm{CO}_{2}$ where the Webb effect is often of the same order as the flux.

Webb et al. (1980) and Lenschow (1995) show that no adjustment to measured flux is required, however, with the determination of a constituent's dry-air mixing ratio. That is, $\bar{w}=0$ for isothermal, dry air conditions. The length of the APIMS sampling line effectively eliminates temperature

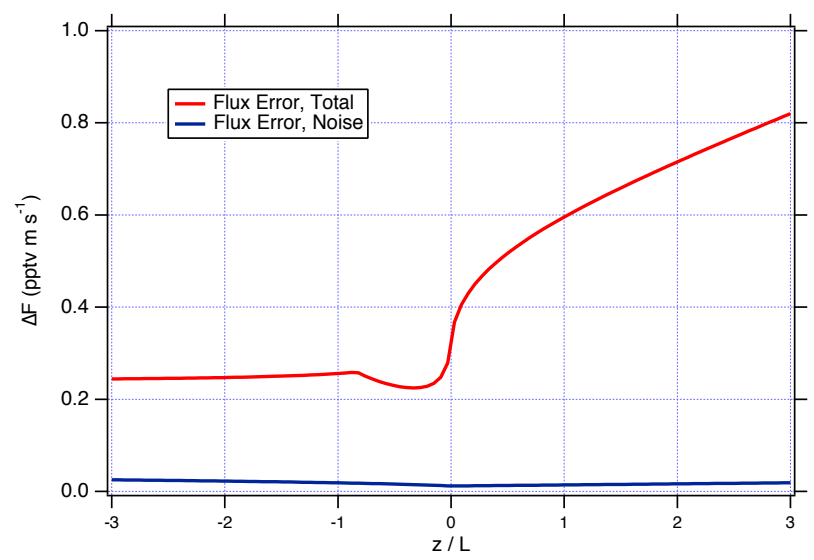

Fig. 8. Computed absolute flux error as a function of atmospheric stability $(z / \mathrm{L})$. Error is computed from Eqs. (23)-(27) for the following conditions: $z=18 \mathrm{~m}, \overline{u_{r}}=8 \mathrm{~m} \mathrm{~s}^{-1}, u^{*}=0.28 \mathrm{~m} \mathrm{~s}^{-1}$, $F_{0}=1$ pptv m s$^{-1}\left(3.6 \mu\right.$ moles $\left.\mathrm{m}^{-2} \mathrm{~d}^{-1}\right)$, and $\phi_{c_{n}}=4 \mathrm{pptv}^{2} \mathrm{~Hz}^{-1}$. The contribution of noise from the second term in Eq. (23) is small and relatively constant as a function of stability.

fluctuations in the sample stream, but the labeled internal standard is diluted to constant concentration in moist air, so to be technically correct the dry-air standard concentration should be used. Drying the sample air can introduce unknown variability into the standard concentration and mass 66 signal related to the variability in water vapor. This may be corrected by low-pass filtering both the mass 66 signal and calibration gas flow rate and then computing standard concentration corrected to dry-air conditions using bulk humidity data, but in most cases the correction is insignificantly small.

\subsection{Motion correction error and motion-gradient effects}

As stated in the introduction, flux is computed as the covariance of vertical wind velocity and concentration or mixing ratio, $F=\overline{w^{\prime} c^{\prime}}$. However, two effects can lead to crosstalk between the measured flux and ship motion: (1) the motion corrections used to derive $w^{\prime}$ are inaccurate, and (2) movement of the sensor up and down in a natural DMS concentration gradient causes an apparent fluctuation in concentration, $c_{\text {mot }}^{\prime}$, that is coherent with motion. Here, we examine the implications of these effects.

Let the measured vertical wind velocity differ from true $w^{\prime}$ by a motion component, $w_{\mathrm{mot}}^{\prime}$, and a correction error, $\delta w_{\mathrm{mot}}^{\prime}$ (28), and the measured fluctuations in DMS be the true fluctuation plus a gradient component related to height above the surface (29).

$$
\begin{aligned}
& w_{\text {meas }}^{\prime}=w^{\prime}+w_{\text {mot }}^{\prime}+\delta w_{\text {mot }}^{\prime} \\
& c_{\text {meas }}^{\prime}=c^{\prime}+\frac{\partial c}{\partial z}(z(t)-\bar{z})
\end{aligned}
$$




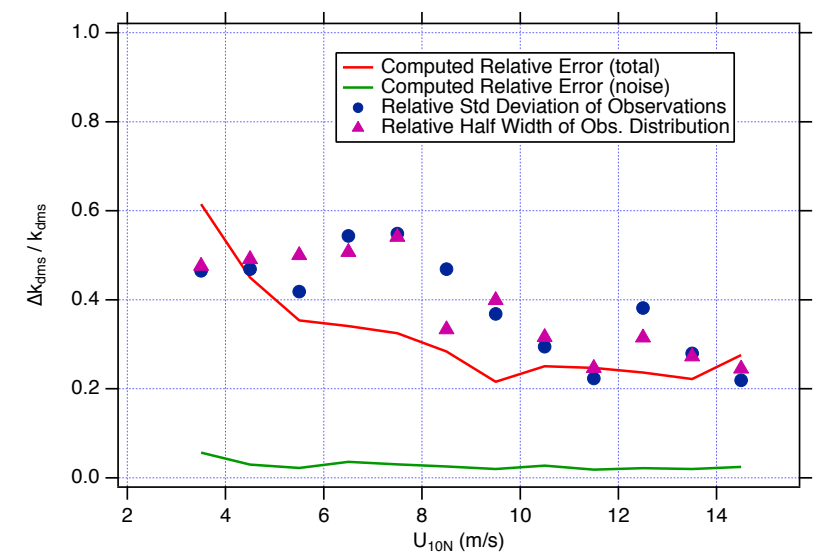

Fig. 9. Computed relative error and RSD of the observations from the Southern Ocean GASEX project. Flux results were selected for a narrow range of sea surface temperatures $\left(4-7^{\circ} \mathrm{C}\right)$. Error was computed for hourly observations $(n=329)$ from Eq. (23) with constant $a=2$. Observed flux and computed error were normalized to the observed sea water DMS concentration, yielding transfer velocity: $k_{\mathrm{dms}}$ and $\Delta k_{\mathrm{dms}}$. These results were binned by the $10-\mathrm{m}$ neutral stability wind speed, $U_{10 \mathrm{~N}}$ and the RSD and distribution half-width of the observed $k_{\mathrm{dms}}$ were computed. Absolute error was further normalized to yield relative error $\left(\Delta k_{\mathrm{dms}} / k_{\mathrm{dms}}\right)$. The computed error (red line) is in general agreement with the RSD and distribution-width of the binned observations (blue and pink symbols). The white noise contribution from the second term in (23) (green line) is less than 20 percent of total computed uncertainty.

The computed flux will then contain errors relating to inaccurate wind correction and vertical displacements in the vertical DMS concentration gradient (30) leading to error in the flux (31).

$\overline{\left(w_{\text {meas }}^{\prime}-w_{\text {mot }}^{\prime}\right) c_{\text {meas }}^{\prime}}=\overline{\left(w^{\prime}+\delta w_{\text {mot }}^{\prime}\right)\left(c^{\prime}+\frac{\partial c}{\partial z}(z(t)-\bar{z})\right)}$

$\delta \overline{w^{\prime} c^{\prime}}=\overline{\delta w_{\operatorname{mot}}^{\prime}\left(\frac{\partial c}{\partial z}(z(t)-\bar{z})\right)}$

From similarity theory, we can express the gradient as a function of the scaling variable friction velocity, $u_{*}(32)$, where the von Karman constant $\kappa \approx 0.4$.

$\frac{\partial c}{\partial z}=-\frac{\overline{w^{\prime} c^{\prime}}}{\kappa u_{*} \bar{z}}$

Furthermore, the height of the sensor can be expressed as the time integral of the vertical motion.

$z(t)-\bar{z}=\int w_{\text {mot }}^{\prime}(t) d t$

So, the fractional error in the flux is given by

$\frac{\Delta F_{c}}{F_{c}}=-\frac{1}{\kappa u_{*} \bar{z}} \overline{\delta w_{\text {mot }}^{\prime} \int w_{\text {mot }}^{\prime}(t) d t}$
For a simple way to estimate this, we can assume the errors in motion are some fraction, $f_{m}$, of the computed motion and further assume the motions are crudely sinusoidal, where $\sigma_{w_{m}}$ is the standard deviation of vertical motion of the sensor and $\omega$ is angular velocity $(\omega=2 \pi f)$.

$\delta w_{\mathrm{mot}}^{\prime} \approx f_{m}\left(\sqrt{2 \sigma_{w_{m}}} \sin (\omega t)\right)$

Integrating the sine function to get the time series of the vertical displacements, yields the following relationship.

$\frac{\Delta F_{c}}{F_{c}}=\frac{f_{m}}{\kappa u_{*} \bar{z}} \frac{2 \sigma_{w_{m}}^{2}}{\omega} \overline{\sin (\omega t) \cos (\omega t)}$

The average of the product of sine and cosine is zero, which leads to the conclusion that motion and concentration terms are in quadrature, or 90 degrees out of phase, and therefore do not contribute to the measured covariance flux. If our assumptions are true, a peak will appear in the quadrature spectrum near the wave frequency, and this is often the case (see Fig. 10). However, we do not expect ship motion to be purely sinusoidal and we do not expect the error in motion corrections to be a simple fraction of the true motions.

To estimate the worst-case magnitude of this error we will assume conditions similar to a recent project in the Southern Ocean when motion conditions were severe (SO-GASEX, day 98). For $f_{m}=0.1 \mathrm{~s}^{-1}, \bar{u}=20 \mathrm{~ms}^{-1}, u_{*}=0.8 \mathrm{~ms}^{-1}, \omega=0.6$ $\mathrm{rad} / \mathrm{sec}, \bar{z}=18 \mathrm{~m}$, and $\sigma_{w_{m}}^{2}=6 \mathrm{~m}^{2} \mathrm{~s}^{-2}$.

$\frac{\Delta F_{c}}{F_{c}}=0.18(2 \overline{\sin (\omega t) \cos (\omega t)})$

If motion and and concentration are in phase rather than in quadrature, the $\overline{\sin (\omega t) \cos (\omega t)}$ term in (37) would be $1 / 2$. Thus, we estimate the maximum flux error to be $\leq 18 \%$ from these effects.

\subsection{Frequency attenuation correction}

As discussed in Sect. 4.3, the APIMS instrument exhibits increasing loss of signal at higher frequencies, largely due to the required air dryer. This may be viewed as equivalent to processing the raw signal with a low pass filter. If the filter function can be determined empirically (Fig. 7), or a reasonable time constant for the filter effect can be estimated, then an inverse operation may be applied to the cospectrum to correct for the loss (Horst, 1997; Bariteau et al., 2009).

The true flux is defined as the integral of the cospectrum from $f=0$ to the Nyquist frequency $\left(f_{n}\right)$ of the time series $w(t)$ and $c_{\mathrm{dms}}(t)$

$F_{\mathrm{dms}}=\overline{w^{\prime} c^{\prime}}=\int_{0}^{f_{n}} C_{w c}(f) d f$

The measured flux will differ from (38) due to the application of the filter function, $\Phi^{2}(f)$. Note the square root of the filter function is used because only DMS is attenuated.

$F_{\mathrm{dms}, m}=\int_{0}^{f_{n}} C_{w c}\left[\Phi^{2}(f)\right]^{1 / 2} d f=\int_{0}^{f_{n}} C_{\mathrm{wcm}}(f) d f$ 


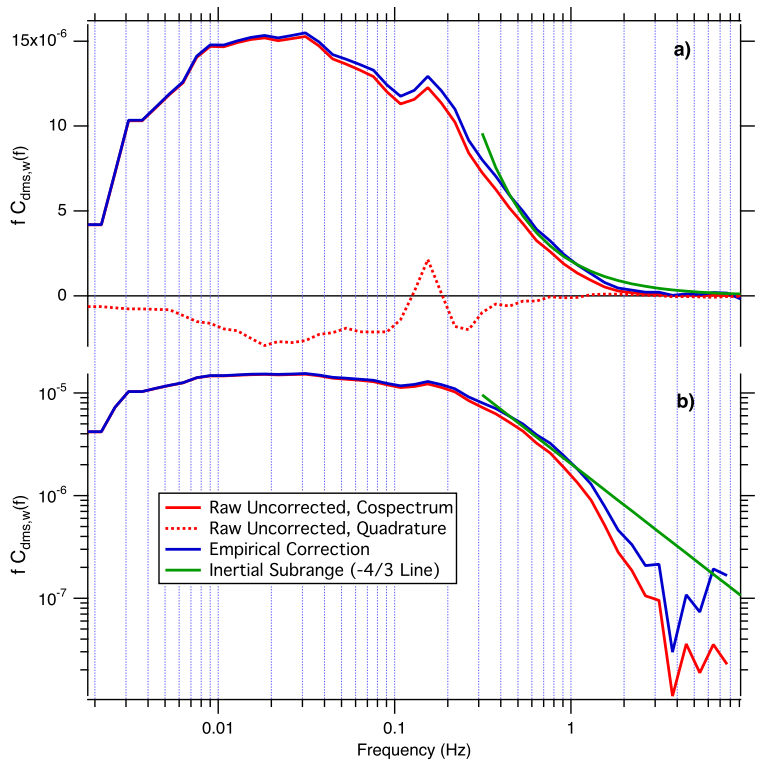

Fig. 10. Mean hourly $(n=294)$ cospectrum and quadrature spectrum for DMS concentration and vertical wind velocity from a cruise in the Sargasso Sea: (a) semilog format (area proportional to covariance), (b) log-log format (linear $-4 / 3$ fall off in the inertial subrange (Kaimal et al. , 1972)). Red traces are uncorrected data. Blue shows the empirical correction for inlet attenuation losses (see Sects. 4.3 and 6.4). The green trace illustrates a further correction to the expected $-4 / 3$ dependence in the inertial subrange. The small peak at $\approx 0.15 \mathrm{~Hz}$ is a spectral feature at the frequency of wave motion which may be due to motion-gradient effects (see Sect. 6.3), but in this case is seen to contribute little error to the mean covariance.

The true spectrum can be estimated as $C_{w c}(f)=C_{\mathrm{wcm}}(f) /\left[\Phi^{2}(f)\right]^{1 / 2}$, such that the estimate for the true flux is obtained as follows.

$F_{\mathrm{dms}}^{\prime}=\int_{0}^{f_{n}} \frac{C_{\mathrm{wcm}}(f)}{\left[\Phi^{2}(f)\right]^{1 / 2}} d f$

In practice, the inverse filter function is only applied to frequencies below $2-3 \mathrm{~Hz}$ since the minimal instrument response above this frequency and large correction merely amplifies noise. Under most conditions there is little flux above $3 \mathrm{~Hz}$ and the correction to DMS flux is usually $5 \%$ or less.

An alternate or additional approach involves fitting the spectrum to the expected form described by Kaimal et al. (1972). Typically, we may expect marine boundary layer to be neutral to slightly unstable; conditions for which the spectral characteristics at low frequencies may be variable and ill-defined. In the inertial subrange, however, the $-4 / 3$ proportionality between $\log \left(f C_{x y}\right)$ and $\log (f)$ should be maintained, allowing a further estimate of missing flux in the high frequency tail. This correction may be significant in high wind conditions and advisable if the empirical response function derived from the square wave signal (Fig. 7) provides insufficient correction.

\subsection{Data screening}

As shown in Sect. 6.1, flux measured as an hourly-average is subject to a significant degree of random error, and we may expect considerable scatter in the results even under homogeneous conditions. Because the lowest frequencies contributing to flux are poorly sampled by an hourly average of ten minute data segments, it is common to see the greatest random variability in the cospectra at these frequencies. One may screen cospectra based on the magnitude of signal at low frequencies, removing the largest outliers, and this has been adopted by at least one group (Marandino et al., 2007). This approach may have merit within a limited data set, improving the precision of the mean. Given a sufficiently large number of measurements, however, low frequency variability will average out, as illustrated by the cross-spectra in Fig. 10, and should not have a biasing effect on the relationship between derived transfer velocities and wind speed, for example.

The principal objective of quality control criteria is identification of conditions which may lead to nonrandom bias. For flux measurements on ships, air flow distortion may be extreme for any wind direction that is not within a narrow sector of the bow. Furthermore, motion corrections during ship maneuvers are often suspect. Experience has shown the best quality data are obtained when the ship is bowto-the-wind and holding station or moving slowly into the wind. If the sea-state is not extreme, cruising into the wind at up to 12 knots is also usually acceptable. The primary quality control criterion, therefore, is relative wind direction (e.g. $\pm 60 \mathrm{deg}$ ). Further restrictions on ship maneuvers (e.g. $<10$ degrees heading change in any 10 min flux window) are useful to exclude conditions where the motion corrections may be suspect. The limits chosen for each criterion often depend on the particulars of the ship and sensor installation.

We expect variance in vertical wind velocity to follow a relatively predictable relationship with wind speed, so $\sigma_{w}$ is often a useful secondary criterion, as is the standard deviation in the motion correction, which may point to increased error from the uncorrected motion-gradient effects mentioned in Sect. 6.3. A careful examination of wind variances can also help define acceptable limits for relative wind direction and ship maneuvers. Finally, computation of friction velocity (for example, by inertial dissipation) is often desirable and serves as an additional diagnostic. A significant change in the relationship between observed $u_{*}$ and bulk-model derived $u_{*}$ (e.g. from the NOAA COARE bulk flux model, Fairall et al., 1996, 2003) may serve as a useful flag for air flow distortion.

With respect to atmospheric conditions, the quantity $F_{c} / z$ mentioned in Sect. 5.2 is a useful flag for situations where the steady state assumption may break down. Finally, depending on the meteorological regime, an assessment of the inversion height may also be required to monitor possible error due to entrainment and the flux gradient. 


\section{Summary}

Atmospheric pressure ionization mass spectrometry with an isotopically labeled internal standard (APIMS-ILS) is a robust and capable analytical system for DMS flux measurement by eddy covariance. In particular, the speed and sensitivity of APIMS-ILS is a significant improvement over earlier analytical methods for atmospheric DMS. Limitations to the actual frequency response of the instrument lead to generally minor losses of high frequency flux information. These losses can be largely corrected if the frequency response of the instrument is known. Further losses at the inertial subrange frequencies may be estimated from the expected spectral characteristics and these corrections may become important for high wind speed conditions.

For studies of sea/air gas exchange, surface flux is the desired quantity, and DMS measurements from ships are seen to be compatible with standard assumptions relating the flux measured at height $z$ with the surface flux. Challenges related to flux measurement from a moving platform are considerable, but motion interferences may be largely corrected during data processing. Residual error from motion artifacts is estimated to be small relative to the typical random error expected for atmospheric boundary layer turbulence statistics.

\section{Appendix A}

\section{APIMS-ILS instrument description}

APIMS instruments currently used for DMS flux measurements are built from a combination of base components supplied by Extrel CMS (http://www.extrel.com/) and a variety of custom-designed components specific to the application. This is more a product of convenience and the long association of Extrel with the research community than of necessity. The descriptions which follow stress the application specific aspects of the instrument design, recognizing other designs better suited to field deployment (e.g. smaller and lighter with less power consumption) will undoubtedly follow from future method development work.

\section{A1 Ionization source}

The ion source for the APIMS is external to the high vacuum chamber. Source design must facilitate the production of ions at or near ambient pressure in a controlled environment and allow for efficient transport of the product ions into the vacuum system and ion optics. Bruins $(1991,1994)$ has reviewed design considerations for APIMS ionization sources and ion sampling efficiency. Figure A1 illustrates the Ni63 source used on the University of Hawaii instrument. The source geometry is based on the Drexel University design, which in turn is a modification of the Extrel corona discharge APIMS source flange. The source illustrated in Fig. A1 bolts directly to the Extrel decluster assembly in place of the corona source. The inlet aperture is the same one used for the corona discharge source.

Dried sample air, at a flow of 3-4 std $\mathrm{L} \mathrm{min}^{-1}$, first passes through a heater section maintained at $400{ }^{\circ} \mathrm{C}$. A stainless screen at the end of the heater smooths out large scale turbulence in the gas flow. Heated gases then pass through a cylindrical foil plated with $15 \mathrm{mCi} \mathrm{Ni}-63$. Ion-molecule reactions responsible for the production of water clusters and protonated DMS occur in this region. A $250 \mu \mathrm{m}$ orifice facing the ionization volume draws about $0.5 \mathrm{std} \mathrm{L} \mathrm{min}^{-1}$ into the decluster chamber. The balance of the gas flow exits the source and passes through a mass flow controller. Gas exiting the flow controller is utilized as a purge flow in the outer jacket of the Nafion air dryer before passing to a vacuum pump. The low pressure of the dried purge flow improves dryer efficiency significantly. The orifice is isolated in a ceramic dielectric ring and connected to a variable DC voltage supply for tuning purposes, but in practice the optimum potential for the orifice is near ground and large bias potentials are unnecessary.

The heater cartridge (Watlow Firerod) features an imbedded thermocouple to facilitate temperature regulation using a programmable PID controller (Omega CN132). With a properly tuned controller, close thermal coupling between the heater and imbedded thermocouple results in extremely stable temperature control $\left(+/-0.2^{\circ} \mathrm{C}\right)$. The source block is independently heated to $150^{\circ} \mathrm{C}$ with two cartridges and a separate PID controller. The gas temperature is not monitored directly and may be less than the heater setpoint, but heater temperatures greater than $400^{\circ} \mathrm{C}$ are not observed to yield further increases in sensitivity.

A desire to maintain high sensitivity and frequency response dictates the rather large flow rates. The source can be redesigned in reduced dimensions to accommodate a smaller source flow, for example as described by Marandino et al. (2007), but the reported sensitivities are not significantly different from those obtained with the source shown here. As part of an overall reduction in instrument size, however, a smaller source has obvious advantages and may lead to improved sensitivity if a greater fraction of the total flow enters the vacuum system. Future instrument development will undoubtedly focus on this issue.

\section{A2 Vacuum system, ion optics and detection}

Figure A2 illustrates the vacuum and ion optical systems of the University of Hawaii APIMS, a design based on the Extrel molecular beam monitoring system. The vacuum system has 3 distinct regions: the decluster assembly with three tunable lens elements and an operating pressure of 5 Torr; the front vacuum chamber with an operating pressure of $10^{-4}$ Torr, pumped by a $500 \mathrm{Ls}^{-1}$ turbomolecular pump (Varian V550), incorporating a series of ion focussing lenses; and the rear vacuum chamber operating at $10^{-7}$ Torr, 


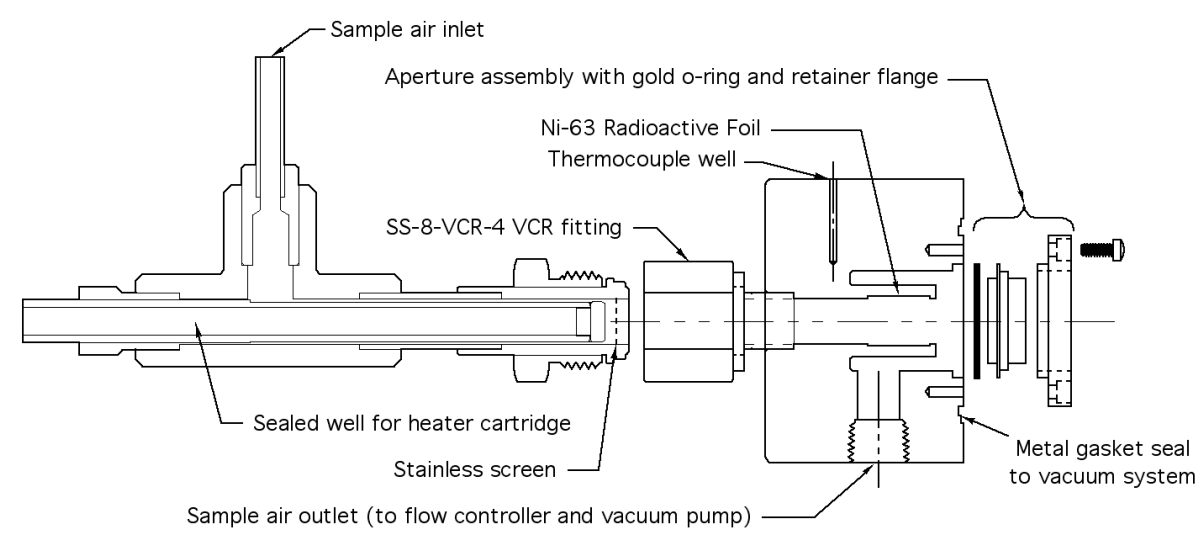

Fig. A1. High temperature inlet and atmospheric pressure ionization source. Sample air flows over a sealed stainless steel tube containing the heater cartridge, then passes to the ionization volume. The ${ }^{63} \mathrm{Ni}$ foil is formed into a cylinder and placed in front of the inlet aperture. The source block bolts to the decluster chamber and seals with an aluminum gasket.

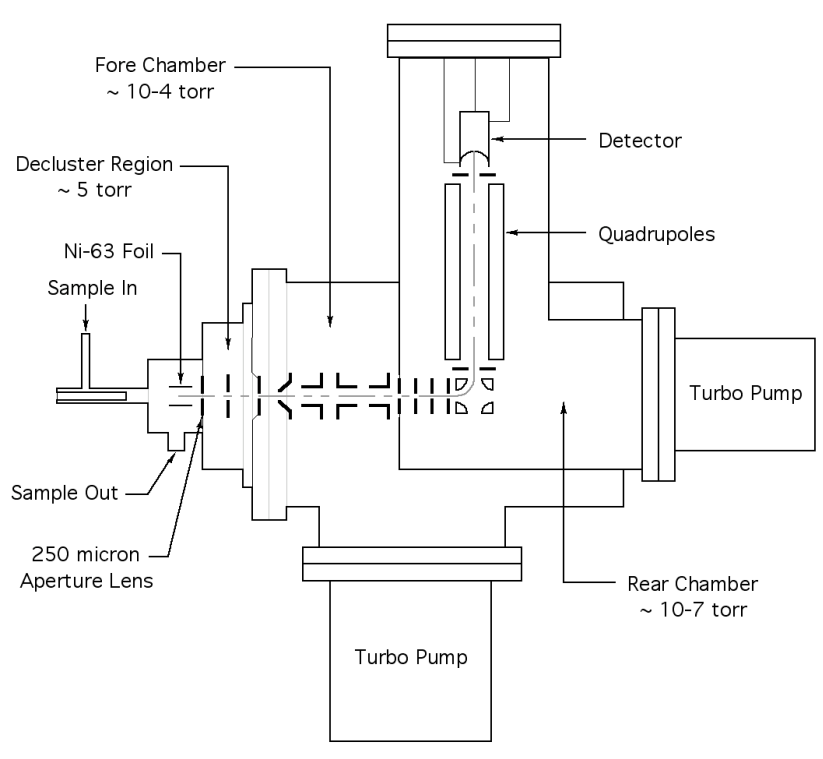

Fig. A2. APIMS vacuum system and ion optics, based on the Extrel molecular beam sampling system. Typical operating pressures are shown.

pumped by a $250 \mathrm{Ls}^{-1}$ turbomolecular pump (Varian V250), with additional focussing lenses, a quadrupole deflector assembly directing ions into a 90 degree bend, the quadrupole mass analyzer with $19 \mathrm{~mm}$ diameter poles, and the electron multiplier (ITT Ceramax $7550 \mathrm{~m}$ ). The quadrupoles are driven by an Extrel RF power supply (300 Watt, $2.1 \mathrm{MHz}$ ) with a mass range of 0-120 AMU. A $1.2 \mathrm{MHz}$ supply, which yields a wider usable mass range with reduced resolution, is equally suitable. Pulse counting electronics are used to quantify the ion current (Advanced Research Instruments MTS100 preamplifier).
The high degree of isolation between the front and rear chambers results in very low rear chamber operating pressures. A single $2 \mathrm{~mm}$ aperture (the chamber aperture lens) is the sole opening between the two regions. The 90 degree bend in ion trajectory allows neutral molecules to stream into the turbo pump, facilitating an on-axis mount for the electron multiplier. The Hawaii instrument is unique in this respect and other instruments (e.g. Bandy et al., 2002) use linear ion optics with essentially the same Extrel quadrupole probe assembly.

The flange mounted decluster chamber is a standard Extrel product based on the work of Ketkar et al. (1989) and is used without modification except for the substitution of a heated radioactive source volume, described above. In the decluster section, collisional dissociation at 5 Torr breaks up the larger, less stable clusters as ions are directed to a second $300 \mu \mathrm{m}$ orifice and into the high vacuum ion optics. As with the ion source, the design of the decluster section could possibly be optimized. The absolute efficiency of ion transmission through the decluster section is unknown, but may be very low. We desire the highest possible sensitivity for flux measurements, and future engineering and design work should be directed at improving efficiency at this step. Significant increases in ion transmission would allow the use of smaller quadrupole systems for comparable overall performance.

\section{A3 Gas flow control}

Gas flows for the analytical system are illustrated in Fig. A3. Measurements critical to the calculation of the ambient mixing ratio are: internal standard, main manifold, and subsample flows. These flow meters and controllers should be calibrated against a well maintained flow standard on a regular basis. Critical control of the calibration gas flow is essential, and experience has shown DC solenoid-type flow controllers, the standard in much of the industry, have a motion 


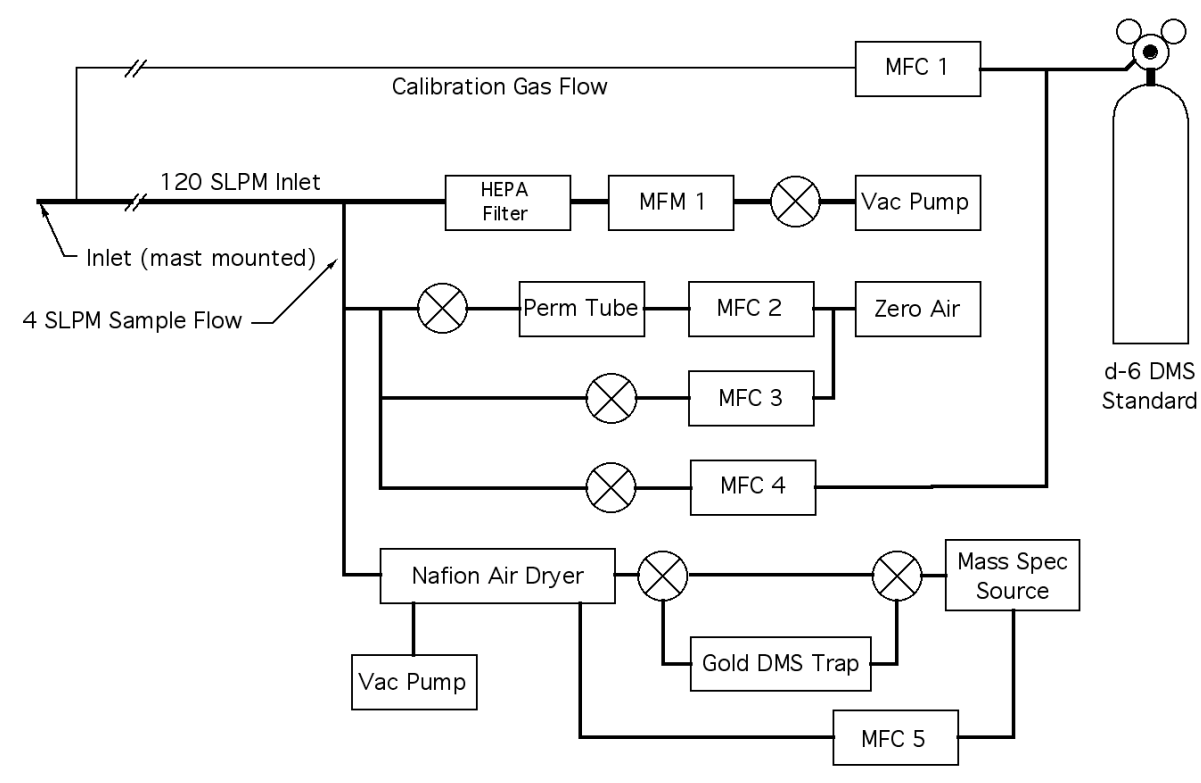

Fig. A3. Gas flow system for sampling and calibration. A high efficiency particle filter (HEPA) is used on the main manifold flow to protect the mass flowmeter MFM 1 from salt aerosols. Three mass flow controllers (MFC 2-4) are included to facilitate calibration of the compressed gas standard using a permeation device. Recycle flow is used for the Nafion dryer outer-jacket, which operates at reduced pressure, improving dryer performance.

sensitivity leading to oscillating flow rates on ships and aircraft. Thermal expansion-type controllers (e.g. Celerity FC$260 \mathrm{~V})$ are superior in this respect. The provision for zero air flow into the point where sample flow is drawn from the main manifold allows the operator to block sample flow with zero air when necessary and facilitates calibration of labeled DMS cylinders using the permeation tube device. It is normal operation procedure to stop all flows for a minute or so each day to record meter zero levels.

\section{A4 Data acquisition and instrument control}

Mass spectrometer control and all data acquisition, including wind and motion measurements, are performed by a National Instruments PXI data acquisition system comprised of the following modules: PXI-1031 Chassis/Power Supply, 8175 RT Controller, two 6052e Data Acquisition cards, and one 6608 Counter/Timer card. Software for mass scans and single-ion monitoring was developed in the LabVIEW RealTime (RT) programming environment.

Wind and motion data are obtained with instrumentation identical to the NOAA-ESRL/PSD portable flux system (Fairall et al., 2003, 2006). Three-axis winds are measured with a Gill R2 sonic anemometer. Six-channel motion measurements (acceleration and angular rate on 3 axes) are obtained with a Systron Donner MotionPak (model MPGCCCQAAB-100). High frequency noise and vibration are removed from the analog motion channels using a $5 \mathrm{~Hz}$ lowpass elliptical filter prior to acquisition (Avens Signal Equip.
Corp. AML-P8E5Hz-D). Flow, motion and wind data are logged as DC analog signals by the 6052e DAQ cards. Ion pulses are totalized with a counter on the 6608 card.

Timing for the data acquisition and control loop is driven by a GPS-synchronized time and frequency receiver (Symmetricom model XL-AK). Each iteration of the control loop sets the command voltage for the appropriate mass (mass 63 for the ambient isotopomer or mass 66 for the d3-labeled internal standard), counts pulses for the specified interval and scans all analog inputs. Two loops are required to compute one mixing ratio value: one loop to measure the internal standard signal intensity and one for the ambient signal. Analog data from the two loops are averaged and saved to disk along with standard and ambient count rates. A $10 \mathrm{kHz}$ GPSdisciplined pulse output from the XL-AK is divided to an appropriate frequency for the loop trigger pulse by a counter on the 6608 (e.g. a $40 \mathrm{~Hz}$ trigger for 20 mixing ratio measurements per second), assuring a precise and synchronized sampling frequency for all data channels.

The 6608 counter/timer card has an on-board clock, synchronized to GPS Universal time with an IRIG-B time code from the XL-AK receiver. The time stamp is read from the IRIG-synchronized clock at each iteration of the control loop.

Acknowledgements. The authors gratefully acknowledge support from NSF grants ATM02-41611 and ATM05-26341, NOAA grant NA07OAR4310084, NOAA's Carbon Cycle Program and NOAA's Health of the Atmosphere Program. We are also grateful for the support of the officers and crew of the NOAA ship 
Ronald H. Brown and the Harbor Branch Oceanographic Institution research vessel R/V Seward Johnson on many field deployments and the work of $\mathrm{M}$. Yang on field deployments in the Pacific. Finally, we would like to thank A. Bandy for his continued support and inspiration.

Edited by: P. Xie

\section{References}

Andreae, M. and Crutzen, P.: Atmospheric aerosols: Biogeochemical sources and role in atmospheric chemistry, Science, 276, 1052-1058, 1997.

Archer, S., Smith, G., Nightingale, P., Widdicombe, C., Tarran, G., Rees, A., and Burkill, P.: Dynamics of particulate dimethylsulphoniopropionate during a lagrangian experiment in the northern North Sea, Deep-Sea Res. Pt. II, 49, 2979-2999, 2002.

Bandy, A., Thornton, D., and Driedger III, A.: Airborne measurements of sulfur dioxide, dimethyl sulfide, carbon disulfide, and carbonyl sulfide by isotope dilution gas chromatography/mass spectrometry, J. Geophys. Res., D12, 23423-23433, 1993.

Bandy, A., Thornton, D., Tu, F., Blomquist, B., Nadler, W., Mitchell, G., and Lenschow, D.: Determination of the vertical flux of dimethyl sulfide by eddy correlation and Atmospheric Pressure Ionization Mass Spectrometry (APIMS), J. Geophys. Res., 107(D24), 4743, doi;10.1029/2002JD002472, 2002.

Bariteau, L., Helmig, D., Fairall, C. W., Hare, J. E., Hueber, J., and Lang, E. K.: Determination of oceanic ozone deposition by shipborne eddy covariance flux measurements, Atmos. Meas. Tech. Discuss., 2, 1933-1972, 2009,

http://www.atmos-meas-tech-discuss.net/2/1933/2009/.

Barnard, W., Andreae, M., Watkins, W., Bingemer, H., and Georgii, H.: The flux of dimethylsulfide from the oceans to the atmosphere, J. Geophys. Res., 87, 8787-8793, 1982.

Bates, T., Lamb, B., Guenther, A., Dignon, J., and Stoiber, R.: Sulfur emissions to the atmosphere from natural sources, J. Atmos. Chem., 14, 315-337, 1992.

Bates, T., Kiene, R., Wolfe, G., Matrai, P., Chavez, F., Buck, K., Blomquist, B., and Cuhel, R.: The cycling of sulfur in surface seawater of the northeast Pacific, J. Geophys. Res., C4, 78357843, 1994

Bates, T., Kapustin, V., Quinn, P. K., Covert, D., Coffman, D. J., Johnson, J., and Wiedensohler, A.: Aerosol physical properties and processes in the lower marine boundary layer: a comparison of shipboard sub-micron data from ACE-1 and ACE-2, Tellus, 52B, 258-272, 2000.

Blomquist, B., Bandy, A., Thornton, D., and Chen, S.: Grab sampling for the determination of sulfur dioxide and dimethyl sulfide in air by isotope dilution gas chromatography/mass spectrometry, J. Atmos. Chem., 16, 23-30, 1993.

Blomquist, B., Fairall, C., Huebert, B., Kieber, D., and Westby, G.: DMS sea-air transfer velocity: Direct measurements by eddy covariance and parameterization based on the NOAA/COARE gas transfer model, Geophys. Res. Lett., 33, L07601, doi:10.1029/2006GL025735, 2006.

Bruins, A.: Mass spectrometry with ion sources operating at atmospheric pressure, Mass Spectrom. Rev., 10, 53-77, 1991.
Bruins, A.: Atmospheric-pressure-ionization mass spectrometry: I. Instrumentation and ionization techniques, Trends Anal. Chem., 13, 37-43, 1994.

Businger, J.: Evaluation of the accuracy with which dry deposition can be measured with current micrometeorological techniques, J. Clim. Appl. Meteorol., 25, 1100-1124, 1986.

Businger, J. and Oncley, S.: Flux measurement with conditional sampling, J. Atmos. Ocean. Tech., 7, 349-352, 1990.

Businger, J., Wyngaard, J., Izumi, Y., and Bradley, E.: Flux profile relationships in the atmospheric surface layer, J. Atmos. Sci., 28, 181-189, 1971.

Charlson, R., Lovelock, J., Andreae, M., and Warren, S.: Oceanic phytoplankton, atmospheric sulfur, cloud albedo and climate, Nature, 326, 655-661, 1987.

Crutzen, P., Williams, J., Pöschl, U., Hoor, P., Fischer, H., Warneke, C., Holzinger, R., Hansel, A., Lindinger, W., Scheeren, B., and Lelieveld, J.: High saptial and temporal resolution measurements of primary organics and their oxidation products over the tropical forests of Surinam, Atmos. Environ., 34, 1161-1165, 2000.

Edson, J. B., Hinton, A. A., Prada, K. E., Hare, J. E., and Fairall, C. W.: Direct covariance flux estimates from mobile platforms at sea, J. Atmos. Ocean. Tech., 15, 547-562, 1998.

Elliott, S.: Dependence of DMS global sea-air flux distribution on transfer velocity and concentration field type, J. Geophys. Res. 114, G02001, doi:10.1029/2008JG000 710, 2009.

Fairall, C., Bariteau, L., Grachev, A., Hill, R., Wolfe, D., Brewer, W., Tucker, S., Hare, J., and Angevine, W.: Turbulent bulk transfer coefficients and ozone deposition velocity in the International Consortium for Atmospheric Research into Transport and Transformation, J. Geophys. Res., 111, D23S20, doi:10.1029/2006JD007597, 2006.

Fairall, C. W., Bradley, E. F., Rogers, D. P., Edson, J. B., and Young, G. S.: Bulk parameterization of air-sea fluxes for TOGA COARE, J. Geophys. Res., 101, 3747-3764, 1996.

Fairall, C. W., Hare, J. E., Edson, J. E., and McGillis, W.: Parameterization and micrometeorological measurement of air-sea gas transfer, Bound.-Lay. Meteorol., 96, 63-105, 2000.

Fairall, C. W., Bradley, E. F., Hare, J. E., Grachev, A. A., and Edson, J. B.: Bulk parameterization of air-sea fluxes: Updates and verification for the COARE algorithm, J. Climate, 16, 571-591, 2003.

Falkowski, P., Kim, Y., Kolber, C., and Wilson, C.: Natural versus anthropogenic factors affecting low-level cloud albedo over the North Atlantic, Science, 256, 1311-1313, 1992.

Faloona, I., Lenschow, D., Campos, T., Stevens, B., van Zanten, M. Blomquist, B., Thornton, D., Bandy, A., and Gerber, H.: Observations of entrainment in eastern Pacific marine stratocumulus using three conserved scalars, J. Atmos. Sci., 62, 3268-3285, 2005.

Ferek, R. and Hegg, D.: Measurements of dimethyl sulfide and $\mathrm{SO}_{2}$ during GTE/CITE-3, J. Geophys. Res., 98, 23435-23442, 1993.

Fogelqvist, E.: Dimethylsulphide (DMS) in the Weddell Sea surface ad bottom water, Mar. Chem., 35, 169-177, 1991.

Gabric, A., Simo, R., Cropp, R., Hirst, A., and Dachs, J.: Modeling estimates of the global emission of dimethylsulfide under enhanced greenhouse conditions, Global Biogeochem. Cy., 18, GB2014, doi:10.1029/2003GB002183, 2004.

Good, A., Durden, D., and Kebarle, P.: Ion-molecule reactions in pure nitrogen and nitrogen containing traces of water at to- 
tal pressure $0.5-4$ Torr. Kinetics of clustering reactions forming $\mathrm{H}^{+}\left(\mathrm{H}_{2} \mathrm{O}\right)_{n}$, J. Chem. Phys., 52, 212-221, 1970.

Gregory, G., Warren, L., Davis, D., Andreae, M., Bandy, A., Ferek, R., Johnson, J., Saltzman, E., and Cooper, D.: An intercomparison of instrumentation for tropospheric measurements of dimethyl sulfide: aircraft results for concentrations at the partsper-trillion level, J. Geophys. Res., 98, 23373-23388, 1993.

Hintsa, E. J., Dacey, J. W. H., McGillis, W. R., Edson, J. B., Zappa, C. J., and Zemmelink, H. J.: Sea-to-air fluxes from measurements of the atmospheric gradient of dimethylsulfide and comparison with simultaneous relaxed eddy accumulation measurements, J. Geophys. Res., 109, doi:10.1029/2002JC001 617, 2004.

Horning, E., Horning, M., Carroll, D., Dzidic, I., and Stillwell, R.: New picogram detection system based on a mass spectrometer with an external ionization source at atmospheric pressure, Anal. Chem., 45, 936-943, 1973.

Horst, T.: A simple formula for attenuation of eddy fluxes measured with first-order-response scalar sensors, Bound.-Lay. Meteorol., 82, 219-233, 1997.

Huebert, B., Blomquist, B., Hare, J., Fairall, C., Johnson, J., and Bates, T.: Measurement of the sea-air DMS flux and transfer velocity using eddy correlation, Geophys. Res. Lett., 31, L23113, doi:10.1029/2004GL021567, 2004.

Kaimal, J., Wyngaard, J., Izumi, Y., and Coté, O.: Spectral characteristics of surface-layer turbulence, Q. J. Roy. Metor. Soc., 98, 563-589, 1972.

Karl, T., Apel, E., Hodzic, A., Riemer, D. D., Blake, D. R., and Wiedinmyer, C.: Emissions of volatile organic compounds inferred from airborne flux measurements over a megacity, Atmos. Chem. Phys., 9, 271-285, 2009, http://www.atmos-chem-phys.net/9/271/2009/.

Kelly, T. and Kenny, D.: Continuous determination of dimethylsulfide at part-per-trillion concentrations in air by atmospheric pressure chemical ionization mass spectrometry, Atmos. Environ., 25A, 2155-2160, 1991.

Ketkar, S., Dulak, J., Fite, W., Buchner, J., and Dheandhanoo, S.: Atmospheric pressure ionization tamdem mass spectrometric system for real-time detection of low-level pollutants in air, Anal. Chem., 61, 260-264, 1989.

Ketkar, S., Penn, S., and Fite, W.: Influence of coexisting analytes in atmospheric pressure ionization mass spectrometry, Anal. Chem., 63, 924-925, 1991.

Kieber, D., Jiao, J., Kiene, R., and Bates, T.: Impact of dimethylsulfide photochemistry on methyl sulfur cycling in the equatorial Pacific Ocean, J. Geophys. Res., C2, 3715-3722, 1996.

Kiene, R. and Service, S.: Decomposition of dissolved DMSP and DMS in estuarine waters: Dependence on temperature and substrate concentration, Mar. Ecol.-Prog. Ser., 76, 1-11, 1991.

Lenschow, D.: Micrometeorological techniques for measuring biosphere-atmosphere trace gas exchange, in: Biogenic trace gases: measuring emissions from soil and water, edited by: Matson, P. and R. Harriss, Chap. 5, 126-163, Blackwell Science, 1995.

Lenschow, D. and Raupach, M.: The attenuation of fluctuations in scalar concentrations through sampling tubes, J. Geophys. Res., 96, 15259-15268, 1991

Lenschow, D. and Spyers-Duran, P.: Measurement techniques: Air motion sensing, NCAR Bulletin 23, National Center for Atmo- spheric Research, P.O. Box 3000, Boulder, CO 80303, 1987.

Lenschow, D. H. and Kristensen, L.: Uncorrelated noise in turbulence measurements, J. Atmos. Ocean. Tech., 2, 68-81, 1985.

Lindinger, W., Hansel, A., and Jordan, A.: On-line monitoring of volatile organic compounds at pptv levels by means of ProtonTransfer-Reaction Mass Spectrometry (PTR-MS): Medical applications, food control and environmental research, Int. J. Mass Spectrom., 173, 191-241, 1998.

Marandino, C., De Bruyn, W., Miller, S., and Saltzman, E.: Eddy correlation measurements of the air/sea flux of dimethylsulfide over the North Pacific Ocean, J. Geophys. Res., 112, D03301, doi:10.1029/2006JD007293, 2007.

Marandino, C., De Bruyn, W., Miller, S., and Saltzman, E.: DMS air/sea flux and gas transfer coefficients from the North Atlantic summertime coccolithophore bloom, Geophys. Res. Lett., 35, D03301, doi:10.1029/2008GL036370, 2008.

Marandino, C. A., De Bruyn, W. J., Miller, S. D., and Saltzman, E. S.: Open ocean DMS air/sea fluxes over the eastern South Pacific Ocean, Atmos. Chem. Phys., 9, 345-356, 2009,

http://www.atmos-chem-phys.net/9/345/2009/.

McGillis, W. R., Edson, J. B., Hare, J. E., and Fairall, C. W.: Direct covariance air-sea $\mathrm{CO}_{2}$ fluxes, J. Geophys. Res., 106, 16729 16745, 2001.

McGillis, W. R., Edson, J. B., Zappa, C. J., Ware, J. D., McKenna, S. P., Terray, E. A., Hare, J. E., Fairall, C. W., Drennan, W., Donelan, M., DeGrandpre, M. D., Wanninkhof, R., and Feely, R. A.: Air-sea $\mathrm{CO}_{2}$ exchange in the equatorial Pacific, J. Geophys. Res., 109, C08S02, doi:10.1029/2003JC002256, 2004.

Miller, S., Marandino, C., de Bruyn, W., and Saltzman, E. S.: Air-sea gas exhcnage of $\mathrm{CO}_{2}$ and DMS in the North Atlantic by eddy covariance, Geophys. Res. Lett., 36, L15816, doi:10.1029/2009GL038 907, 2009.

Mitchell, G. M.: Determination of vertical fluxes of sulfur dioxide and dimethyl sulfide in the remote marine atmosphere by eddy correlation and airborne isotopic dilution atmospheric pressure ionization mass spectrometer, $\mathrm{PhD}$, Drexel University, Philadelphia, PA, USA, 2001.

Putaud, J.-P. and Nguyen, B.: Assessment of dimethylsulfide sea-air exchange rate, J. Geophys. Res., 101, 4403-4411, 1996.

Spicer, C., Kenny, D., Shaw, W., Busness, K., and Chapman, E.: A laboratory in the sky; New frontiers in measurements aloft, Environ. Sci. Technol., 28, 412A-420A, 1994.

Spicer, C., Kenny, D., Chapman, E., Busness, K., and Berkowitz, C.: Observations of dimethyl sulfide over the western North Atlantic Ocean using an airborne tamdem mass spectrometer, J. Geophys. Res., D22, 29137-29147, 1996.

Stevens, B., Lenschow, D., Faloona, I., Moeng, C., Lilly, D., Blomquist, B., Vali, G., Bandy, A., Campos, T., Gerber, H., Haimov, S., Morley, B., and Thornton, D.: On entrainment rates in nocturnal marine stratocumulus, Q. J. Roy. Meteor. Soc., 129, 3469-3493, doi:10.1256/qj.02.202, 2003.

Sunner, J., Ikonomou, G., and Kebarle, P.: Sensitivity enhancements obtained at high temperatures in atmospheric pressure ionization mass spectrometry, Anal. Chem., 60, 1308-1313, 1988a.

Sunner, J., Nicol, G., and Kebarle, P.: Factors determining relative sensitivity of analytes in positive mode atmospheric pressure ionization mass spectrometry, Anal. Chem., 60, 1300-1307, 1988b.

Taddei, S., Toscano, P., Gioli, B., Matese, A., Miglietta, F., Vaccari, F. P., Zaldei, A., Custer, T., and Williams, J.: Carbon dioxide and 
acetone air-sea fluxes over the Southern Atlantic, Environ. Sci. Technol., 43, 5218-5222, 2009.

Webb, E., Pearman, G., and Leuning, R.: Correction of flux measurements for density effects due to heat and water vapour transfer, Q. J. Roy. Meteor. Soc., 106, 85-100, 1980.

Werle, P., Mücke, R., and Slemr, F.: The limits of signal averaging in atmospheric trace-gas monitoring by tunable diode-laser absorption spectroscopy (TDLAS), Appl. Phys., B57, 131-139, 1993.

Williams, J., Pöschl, U., Crutzen, P., Hansel, A., Holzinger, R., Warneke, C., Lindinger, W., and Lelieveld, J.: An atmospheric chemistry interpretation of mass scans obtained from a proton transfer mass spectrometer flown over the tropical rainforest of Surinam, J. Atmos. Chem., 38, 133-166, 2001.

Wyngaard, J.: On surface-layer turbulence, in: Workshop on Micrometeorology, edited by: Haugen, D., Am. Meteor. Soc., 101149, 1973.
Zemmelink, H., Gieskes, W., Klaassen, W., de Groot, H., de Baar, H., Dacey, J., Hintsa, E., and McGillis, W.: Simultaneous use of relaxed eddy accumulation and gradient flux techniques for the measurement of sea-to-air exchange of dimethyl sulphide, Atmos. Environ., 36, 5709-5717, 2002.

Zemmelink, H., Dacey, J., and Hintsa, E.: Direct measurements of biogenic dimethylsulphide fluxes from the oceans: a systhesis, C. J. Fish. Aquat. Sci., 61, 836-844, 2004a.

Zemmelink, H. J., Gieskes, W. W. C., Klaassen, W., Beukema, W. J., de Groot, H. W., de Baar, H. J. W., Hintsa, E. J., McGillis, W. R., and Dacey, J. W. H.: Relaxed eddy accumulation measurements of the sea-to-air transfer of dimethylsulfide over the northeastern Pacific, J. Geophys. Res., 109, C01025, doi:10.1029/2002JC001616, 2004b. 